\title{
DIE LITERARISCHE ÜBERSETZUNG - THEORIE EINER KUNSTGATTUNG (AusZug) A TraduÇão LiterÁria - TEORIA dE UM GÊNERo ARTístico (eXcerto)
}

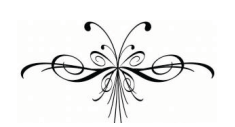

JIŘí LEVÝ

FiliPE NECKEL, MARCELo RoNDinelLi (TRADUTORES)

\section{Die drei Phasen der Übersetzerarbeit}

$(1963,1969)$

Nachdem wir den Entstehungsprozeß der Übersetzung beschrieben haben, können wir versuchen, einige Forderungen zu formulieren, die an die Arbeit des Übersetzers gestellt werden. Wenn wir von der These ausgehen, daß die Vorlage das Material bildet, das er künstlerisch zu bearbeiten hat, dann können wir die Forderungen, die an die übersetzung gestellt werden, in drei Punkten zusammenfassen:

1. Erfassen der Vorlage,

2. Interpretation der Vorlage,

3. Umsetzung der Vorlage.

\section{AS TRÊS FASES DO TRABALHO TRADUTÓRIO \\ (2012)}

Após descrevermos o processo de formação da tradução, podemos tentar formular alguns requisitos que se colocam ao trabalho do tradutor. Se partirmos da tese de que o modelo forma o material com o qual este irá trabalhar artisticamente, então podemos resumir os requisitos que se apresentam na tradução em três pontos:

1. Apreensão do modelo,

2. Interpretação do modelo,

3. Transposição do modelo. 


\section{Das Erfassen der Vorlage}

Vom Künstler, der das Originalwerk geschaffen hat, verlangen wir, daß er die Wirklichkeit, die er darstellt, erfaßt hat vom Übersetzer, daß er das Werk erfaßt, das er verdolmetscht. Ein guter Übersetzer muß vor allem ein guter Leser sein. Der Leser bekommt den Text in die Hand, und aus dem, was über den Prozeß der Aufnahme gesagt wurde, geht hervor, daß der Übersetzer in drei Stufen in den Sinn des Werks eindringt (was indessen nicht besagt, daß diese drei Etappen gesondert und bewußt verlaufen müssen.)

a) Die erste Stufe ist das wörtliche, d. h. das philologische Erfassen des Textes. Das philologische Verstehen erfordert keine besondere Begabung; es ist Sache der fachlichen Vorbereitung und handwerklichen Praxis. Gründen:

Übersetzungsfehler entstehen am häufigsten aus folgenden

A. Irrtümer durch Verwechslung gleich- oder ähnlich klingender Wörter:

1. Unrichtige Wahl zwischen verschiedenen Bedeutungen eines Wortes, z.B. siège $=1$. Wohnsitz, 2. Belagerung

2. Verwechslung ähnlich klingender Wörter der fremden Sprache: found (Vergangenheit von to find) und found (gründen).

3. Bei verwandten Sprachen auch die Verwechslung von in beiden Sprachen ähnlich klingenden Wörtern: joke (engl. = Scherz) und das Joch.

\section{A apreensão do modelo}

Do artista que criou a obra original, esperamos que ele apreenda toda a realidade que representa. Do tradutor, que ele apreenda a obra que traduz. Um bom tradutor deve ser, sobretudo, um bom leitor. O leitor recebe o texto em suas mãos e, a partir do que foi dito sobre o processo de recepção, depreendese que o tradutor penetra no sentido da obra percorrendo três etapas (o que não quer dizer que estas precisem se desenvolver isoladas e de modo consciente).

a) A primeira etapa é a literal, isto é, a apreensão filológica do texto. O entendimento filológico não requer nenhum talento especial; é caso de preparo técnico e prática artesanal.

Os erros de tradução ocorrem principalmente pelas seguintes razões:

A. Equívocos por confusão entre palavras sonoramente iguais ou semelhantes:

1. Escolha incorreta entre significados diferentes de uma palavra, por exemplo, siège $=1$. domicílio, 2. cerco.

2. Confusão entre palavras sonoramente semelhantes da língua estrangeira: found (passado de to find) e found (fundar).

3. Em línguas aparentadas também a confusão entre palavras sonoramente semelhantes em ambas as línguas: joke $($ inglês $=$ brincadeira $)$ e das Joch $($ alemão $=j u$ go). 
B. Irrtümer durch unrichtiges Erfassen des Kontexts:

4. Falsche Einordnung eines Wortes in den Satz bzw. in einen längerer Textabschnitt.

5. Falsche Wortwahl im Hinblick auf das Lebensmilieu des Werks (sachliche Irrtümer).

6. Unrichtige Einordnung eines Wortes in das Anschauungssystem des Autors (Nichtbegreifen der Absichten, der Poetik u. a.).

Man muß damit rechnen, daß eine wortgetreue Übersetzung noch nicht das Verständnis eines Textes beweist:

Wenn wir gefragt werden: $>$ Was meinen sie mit diesem oder jenem $<$, z. B. mit $>$ Verstehen $<$, so können wir gewöhnlich antworten, indem wir ein paar andere Wörter angeben, die, wie uns die Erfahrung gelehrt hat, an seiner Stelle verwendet werden können ... es folgt aber daraus nicht im geringsten, daß wir irgendwelche genauen Vorstellungen von der Sache haben, weil wir diese Ausdrücke liefern können. Dieses $>$ Wörterbuch-Verständnis $<$, wie es genannt werden kann, ist schon seit langem als trügerischer Ersatz für authentischere Arten des Verstehens in den elementaren Stufen all jener Wissenschaften erkannt worden, in denen Definitionen erfordert werden ${ }^{1}$.

Jeder Übersetzer sieht sich in der Praxis oft vor Situationen gestellt, in denen er sich über den tatsächlichen Sinn eines Texts nicht im klaren ist und blind ein dem Wörterbuch entsprechendes Äquivalent setzt.
B. Equívocos por apreensão incorreta do contexto:

4. Colocação equivocada de uma palavra na frase, ou em um segmento mais longo de texto.

5. Escolha equivocada de palavras em relação ao meio em que a obra se insere (equívocos objetivos).

6. Colocação incorreta de uma palavra no sistema de crenças do autor (Não entendimento das intenções, da poética, etc.).

Assim, deve-se contar com a eventualidade de que uma tradução palavra por palavra ainda não ateste a compreensão de um texto:

Se nos perguntam 'o que você quer dizer com isto ou aquilo?', com 'compreender', por exemplo, podemos responder em geral apresentando algumas outras palavras, que, conforme a experiência nos ensinou, podem ser utilizadas em seu lugar... Daí não se pode depreender, de modo nenhum, que possuímos quaisquer conceitos exatos da coisa apenas por podermos fornecer essas expressões. Essa compreensão "de dicionário", como pode ser chamada, já foi identificada há muito tempo como substituto ilusório para modos mais autênticos de compreender nos estágios elementares de todas aquelas ciências nas quais se exigem definições ${ }^{1}$.

Na prática, todo tradutor frequentemente se vê diante de situações nas quais tem dúvidas quanto ao significado real de um texto, lançando-se cegamente a um equivalente, no dicionário, que lhe corresponda.

${ }^{1}$ I. A. RICHARDS. Practical Criticism. London, 1929, 327. 
b) Beim richtigen Lesen eines Textes erfaßt der Leser auch die stilistischen Werte des sprachlichen Ausdrucks, d. h. Stimmungen, ironische oder tragische Untertöne, Appelle an den Leser oder trockenes Konstatieren usf. Der Durchschnittsleser braucht sich diese Qualitäten nicht mit dem Verstande bewußt zu machen, doch der Übersetzer sollte fähig sein, sie rational zu erkennen und zu bestimmen, mit welchen Mitteln der Autor sie erzielt. Die Übersetzung erfordert nicht nur ein gründlicheres, sondern vor allem ein bewußteres Erkennen des Werks als die bloße Lektüre.

Manchmal haben auch scheinbar zufällige Eigenheiten im Ausdruck ihre Funktion, und das höhere Ganze kann durch ihre Unterdrückung gestört werden. In der Hexenszene im IV. Akt des Macbeth lesen wir die Verse:

Thrice the brinded cat has mewed.

Thrice and once the hedge-pig whined.

Nur wenige Übersetzer sind sich des Sinns der Zahlen in diesem Verspaar bewußt. Deshalb ist die Wiedergabe in den Shakespeareübersetzungen aller Sprachen so schwankend. Richtig übersetzte Tieck:

Der scheckige Katz' hat dreimal miaut.

Dreimal und einmal der Igel gequiekt.

Ernst Ortlepp, vielleicht durch die unrichtige Interpunktion in manchenm Shakespeareausgaben irregeführt, verstand die aufgeteilte Zahl im zweiten Vers nicht und bezog offensichtlich das »dreimal« noch auf den vorhergehenden Vers:

Dreimal hört' ich die Katze schrein,

Und einmal grunzte das Stachelschwein. b) Pela leitura correta de um texto, o leitor apreende também os valores estilísticos da expressão verbal; isto é, estados de ânimo, subtons irônicos ou trágicos, apelos ao leitor ou constatações lacônicas, etc. O leitor médio não necessita tomar consciência destas características; porém, o tradutor deve ser capaz de reconhecê-las racionalmente e determinar a partir de quais recursos o autor chegou a elas. A tradução exige uma percepção não só mais minuciosa, mas também, e acima de tudo, mais consciente da obra, do que a mera leitura.

Às vezes, mesmo peculiaridades aparentemente casuais na expressão possuem a sua função, e o todo maior pode ser prejudicado por sua supressão. Na cena das bruxas no Quarto Ato de Macbeth, lemos estes versos:

Thrice the brinded cat has mewed.

Thrice and once the hedge-pig whined.

Apenas poucos tradutores estão cientes do sentido dos números nestes dois versos. Por isso varia tanto a reprodução nas traduções de Shakespeare para todas as línguas. Acertou Tieck quando assim traduziu:

Der scheckige Katz' hat dreimal miaut.

Dreimal und einmal der Igel gequiekt.

Ernst Ortlepp, talvez induzido a erro pela pontuação incorreta de algumas edições de Shakespeare, não compreendeu o número dividido no segundo verso e visivelmente manteve a referência ao dreimal do verso anterior:

Dreimal hört' ich die Katze schrein,

Und einmal grunzte das Stachelschwein 

sche:

Ähnlich übersetzt auch Maurice Maeterlinck ins Französi-

Trois fois le chat miaula.

Le hérisson piaula.

Friedrich Bodenstedt zählte die Lautäußerungen des Igels zusammen und übersetzte zwar mathematisch korrekt, aber von der Funktion dieses Motivs her unrichtig:

Dreimal hat die Katze miaut.

Viermal hat der Igel gequiekt.

Die magische Zahl drei und die ausschließliche Verwendung ungerader Zahlen wurde nämlich für übernatürliche Wesen als typisch angesehen. Die Unterdrückung symbolischer Zahlen entwertet das charakteristische Merkmal der Beschwörungsformel.

c) Über das Erfassen der stilistischen und inhaltlichen Werte der einzelnen Sprachmittel und Teilmotive hinaus führt dann der Weg zum Verständnis des künstlerischen Ganzen, d. h. zum Verstehen der im Werk ausgedrückten Realitäten, wie z. B. der Gestalten, ihrer Beziehungen zueinander, des Milieus der Handlung und des ideologischen Standpunkts des Autors. Diese Art des Textverständnisses ist die schwierigste, denn ebenso wie jeder Leser neigt auch der Übersetzer zu einem Atomisieren der Worte und Motive, und es wird ein beträchtliches $\mathrm{Ma} ß$ an Phantasie beim Leser vorausgesetzt, wenn er die künstlerische Realität des Werks voll erfassen soll. Es ist beispielsweise nicht allzu schwierig, den Stilwert einer Replik allein zu verstehen, aber es ist bereits schwer, aus
De modo semelhante traduziu também Maurice Maeterlinck para o francês:

Trois fois le chat miaula.

Le hérisson piaula.

Friedrich Bodenstedt somou as vocalizações do porcoespinho e, apesar de traduzir matematicamente de forma correta, a função deste motivo fica incorreta:

Dreimal hat die Katze miaut.

Viermal hat der Igel gequiekt.

O número mágico "três" e o emprego exclusivo de números ímpares eram considerados como típicos de seres sobrenaturais. A supressão de números simbólicos invalida a marca característica da fórmula de conjuração.

c) Além da apreensão dos valores referentes a estilo e conteúdo de cada um dos recursos de linguagem e dos motivos parciais, este caminho leva ao entendimento do todo artístico, isto é, à compreensão das realidades expressas na obra, como, por exemplo, dos personagens, das suas relações entre si, do meio em que a ação se desenvolve e do ponto de vista ideológico do autor. Este modo de compreensão textual é o mais difícil, pois, assim como qualquer leitor, o tradutor é inclinado a uma atomização das palavras e motivos, e se pressupõe um considerável grau de fantasia por parte do leitor, quando este procura apreender integralmente a realidade artística da obra. Não é tão difícil, por exemplo, compreender o valor estilístico de uma imitação isoladamente; porém, já é bem mais complicado ima- 
allen Repliken und Handlungen sich die Vorstellung von dem Charakter einer Gestalt zu bilden. Die Vorstellungsgabe ist für den Übersetzer ebenso unentbehrlich wie für den Regisseur, und ohne sie kann er nur schwer zu einem umfassenden Verständnis eines Werks gelangen. Bei der üblichen Forderung, der Übersetzer solle sich mit den Gegebenheiten des Milieus, aus dem er übersetzt, bekannt machen, geht es eigentlich darum, daß er die im Werk enthaltenen Realitäten unmittelbar erkennt und daher deren Widerspiegelung im Werk rekonstruieren kann.

In allen Fällen von Übersetzerirrtümern wirken zwei Faktoren zusammen: das Unvermögen des Übersetzers, sich die Wirklichkeit oder das Anliegen des Autors vorzustellen, und irrige, von der Sprache des Originals ausgehende Gedankenverbindungen, seien sie nun durch zufällige Sprachähnlichkeiten oder durch eine tatsächliche Vieldeutigkeit des Textes verursacht. Der Hauptunterschied zwischen dem schöpferischen und dem mechanischen Übersetzer besteht darin, daß sich der schöpferische Übersetzer auf dem Wege vom Original zur Übersetzung die Wirklichkeit, von der er schreibt, vorstellt, daß er also über den Text hinaus zu den Gestalten, Situationen und Ideen vordringt, während der unschöpferische Übersetzer den Text nur mechanisch aufnimmt und lediglich Wörter übersetzt. Für die künstlerische Erziehung der Übersetzer würde sich hieraus die Forderung ableiten, daß die Formel des psychologischen Prozesses: Originaltext - Text der Übersetzung, in eine schwierige, aber künstlerisch allein gültige: Originaltext - vorgestellte Wirklichkeit Text der Übersetzung, abgeändert werden muß. Der Übersetzer neigt natürlicherweise zum erstgenannten Schema, da es das bequemere ist. Die Rekonstruktion der Wirklichkeit hingegen erfordert Vorstellungskraft und eine durchdachte Interpretation des ginar o caráter de um personagem a partir de todas as imitações e ações. O dom da imaginação é, para o tradutor, tão indispensável quanto para o diretor e sem ele aquele dificilmente consegue chegar a uma compreensão abrangente de uma obra. Em relação aos requisitos usuais de que o tradutor deve se familiarizar com os dados do meio de onde traduz, trata-se, na verdade, de identificar imediatamente as realidades contidas na obra e, por conseguinte, conseguir reconstruir seu reflexo na obra.

Em todos os casos de equívocos em traduções, dois fatores interagem: a incapacidade do tradutor de imaginar a realidade ou o desejo do autor; e as associações de ideias equivocadas partindo da língua do original, causadas por semelhanças linguísticas casuais ou por uma efetiva polissemia do texto. A principal diferença entre o tradutor criativo e o que trabalha maquinalmente consiste no fato de que o tradutor criativo, em seu caminho do original à tradução, apresenta a realidade sobre a qual escreve, indo além do texto, até os personagens, situações e ideias; enquanto que o tradutor não criativo apreende o texto apenas de uma maneira maquinal, simplesmente traduzindo palavras. Para a educação artística dos tradutores, haveria a exigência de que a fórmula do processo psicológico Texto original - Texto da tradução fosse alterada para uma mais complexa, porém artisticamente mais válida: Texto original - Realidade imaginada - Texto da Tradução. Naturalmente, o tradutor tende ao primeiro esquema, visto ser este mais confortável. A reconstrução da realidade, pelo contrário, requer criatividade e uma interpretação do texto produzida por reflexão muito aprofundada. 
Textes.

Es ist eine der ersten Voraussetzungen der Ästhetik des Übersetzens, daß der Übersetzer die Methodik der Rekonstruktion der Wirklichkeit durcharbeitet. Dabei geht es freilich darum, daß der Übersetzer nicht nur eine ganz konkrete Vorstellung von den Gestalten, den Ursachen der zwischen ihnen bestehenden Konflikte, dem Milieu, in dem sich die Handlung vollzieht usw. gewinnt, sondern auch von der Anordnung der Information über diese Fakten im Werk, also davon, wie der wahre Charakter, die wahre Motivierung der Handlung usf. dem Leser allmählich enthüllt oder vorübergehend verheimlicht werden. Andernfalls kann es nämlich oft geschehen, daß der Übersetzer sich durch seine Kenntnisse des Milieus verleiten läßt, in das Werk Fakten hineinzuinterpretieren, die darin nicht ausgesprochen werden. Weil er den ganzen Handlungsablauf und die Lösung der Konflikte kennt, hat er manchmal eine klare Vorstellung von dem Helden des Werks, doch vergißt er, daß der Autor ihn erst allmählich vor dem Leser beleuchtet, daß er für eine bestimmte Zeit seine Beziehungen $\mathrm{zu}$ ihm oder die Beziehungen der verschiedenen Gestalten untereinander absichtlich geheimhält, daß somit der Gesamtplan des Autors nicht bewußt gemacht wird. Der Übersetzer jedoch verrät häufig mit Hilfe von stilistischen Mitteln diese Beziehungen früher, als es ratsam ist. Solch ein übersetzerisches $>$ Vorausblicken $<$ ist das Ergebnis eines einseitig sachlichen Erfassens der Gestalt.

Bewußt wahrte Friedhelm Kemp bei seiner Übersetzung des Gedichts $>$ Hier régnant désert $<$ von Yves Bonnefoy die Ausdrucksfunktion der offenen Form:
É um dos primeiros pré-requisitos da estética do traduzir que o tradutor estude a fundo a metodologia de reconstrução da realidade. Cumpre em todo caso ao tradutor obter não somente uma representação bem concreta dos personagens, dos motivos de conflitos existentes entre estes, do lugar onde se dá a ação, mas também do arranjo da informação sobre esses fatos na obra, ou seja, o modo como o verdadeiro caráter, a verdadeira motivação da ação, etc., são gradativamente revelados ou temporariamente ocultados do leitor. Por outro lado, muitas vezes pode acontecer de o tradutor deixar-se conduzir por seu conhecimento do lugar, acrescentando na obra, por força de sua interpretação, fatos que não são expressos. Por conhecer todo o curso da ação e a solução dos conflitos, às vezes ele possui uma clara ideia do herói da obra, esquecendo-se, porém, de que o autor só aos poucos o ilumina ao leitor, que aquele, por um determinado tempo, mantém intencionalmente em segredo suas relações com este ou as relações dos diferentes personagens entre si, fazendo com que o plano geral do autor não se torne aparente. Entretanto, com o auxílio de recursos estilísticos, o tradutor frequentemente revela estas relações mais cedo do que o aconselhável. Tal "antevisão" tradutória é resultado de uma apreensão objetiva unilateral do personagem.

Foi de modo consciente que Friedhelm Kemp preservou em sua tradução do poema "Hier régnant désert", de Yves Bonnefoy, a função expressiva da forma aberta: 
Bien des astres ont franchi La terre toujours niable, Mais toi tu as gardé pure Une antique liberté

\section{Es-tu végétable, tu}

As des arbres la patience

D'être ici liée, mais libre

Parmi les vents les plus hauts.

Et comme naître impatient

Bouleverse le sol,

Toi de tes yeux tu dénies

Le poids des glaises d'étoiles.
Manches Gestirn überstieg

Die immer verneinbare Erde,

Du aber hast dir rein bewahrt

Eine unvordenkliche Freiheit.

Du Pflanzenhafte, denn du hast

Wie Bäume die Geduld, hier

Gebunden zu sein und frei doch

Zwischen den höchsten Winden

Und wie Geburt unduldsam

Den Boden sprengt, so

Verneinste mit deinen Augen du

Die Last der Sternen-Schollen.

\section{Hierzu ergänzt der Übersetzer:}

Die Angeredete übrigens, die pflanzenhaft Geduldige, kehrt in vielen Gedichten des gleichen Zyklus wieder; sie hat keinen eigentlichen Namen; sie ist eine Gestalt, eine Kraft, ist Geliebte, Muse, weibliches Inbild, Element und Stimme, die eigene Seele vielleicht, ist, wenn man sie denn unbedingt allegorisch verstehen will, letzten Endes die Dichtung selber, hier gebunden und frei doch zwischen den höchsten Winden ... Vor allem aber galt es, im Nachgang dem je einzelnen Schritt niemals voraussein zu wollen, im Vertrauen, daß zu den genau gesetzten Einzelheiten auch im Deutschen der Hintergrund eines Sinnes sich einstellen werde ... wenn ich nur bestrebt war, alle Lücken offenzuhalten, und es vermied, in der Wortwahl jeder Verlockung zur Erläuterung oder Erklärung nachzugeben ${ }^{2}$.

Erst wenn der Übersetzer die Wirklichkeit in jener Form erfaßt, in der sie im Werk ausgeführt ist, kann er eine künstlerisch wahre Übersetzung schaffen.

Bien des astres ont franchi La terre toujours niable,

Mais toi tu as gardé pure

Une antique liberté

Es-tu végétable, tu

As des arbres la patience

D'être ici liée, mais libre

Parmi les vents les plus hauts.

Et comme naître impatient

Bouleverse le sol,

Toi de tes yeux tu dénies

Le poids des glaises d'étoiles.
Manches Gestirn überstieg

Die immer verneinbare Erde,

Du aber hast dir rein bewahrt

Eine unvordenkliche Freiheit.

Du Pflanzenhafte, denn du hast

Wie Bäume die Geduld, hier

Gebunden zu sein und frei doch

Zwischen den höchsten Winden.

Und wie Geburt unduldsam

Den Boden sprengt, so

Verneinste mit deinen Augen du

Die Last der Sternen-Schollen.

\section{E completa o tradutor:}

Aquela tratada, aliás, por pflanzenhaft Geduldige [paciente como uma planta], reaparece em muitos poemas do mesmo ciclo; ela não tem de fato um nome; ela é uma personagem, uma força, é amada, musa, ideal feminino, elemento e voz, a própria alma, talvez, caso se queira entendê-la incondicionalmente de modo alegórico; é, em última análise, a própria poesia, aqui fixa e livre por entre os mais altos ventos... Mas era preciso, sobretudo, nunca desejar estar um passo à frente, confiando que, para os detalhes minuciosamente colocados, também no alemão o pano de fundo do sentido se ajustaria... se eu me esforçasse para manter todas as lacunas abertas, evitando ceder a qualquer tentação de esclarecimento e explicação na escolha de palavras ${ }^{2}$.

Apenas quando o tradutor apreende a realidade naquela forma em que ela está produzida na obra ele consegue criar uma tradução artisticamente verdadeira.

${ }^{2}$ F. KEMP. Vom Übersetzen französischer Dichtung, in: Die Kunst der Übersetzung. Munique 1962, 105-106.

Scientia Traductionis, $n .11,2012$ 
Konkrete pädagogische Mittel, die zu diesem Erfassen der Wirklichkeit hinführen könnten, müssen erst erarbeitet werden. Eines von ihnen wird sicher die Übung in der dramaturgischen Interpretation von Schauspielen bilden, das intensive Durchdenken literarischer Werke. Ein Bestandteil dieser Ausbildung würde in eingehenden Analysen der inneren und äußeren Charakteristiken der Helden bestehen, in Beschreibungen des Orts der Handlung und der Situationen, in feinsinnigen Analysen der Beziehungen zwischen den Gestalten, zwischen Handlung und Szenerie, Autor und Werk, Werk und Zeit, in einer Analyse der Widerspiegelung eines fremden Milieus im Werk, in einer Analyse der Idee des Werks usf. Zur Aufdeckung verborgener Textbedeutungen und zur Entwicklung der Phantasie des Übersetzers wird es wohl möglich sein, ähnliche Methoden zu finden, wie Stanislavskij sie zur Heranbildung von Schauspielern angewendet hat.

Wie schon die Versuche von I. A. Richards aus dem Jahre 1929 zeigten, versteht ein großer Teil der Leser von Literatur, besonders von Poesie, eigentlich nicht, was er liest:

... wir können die weitverbreitete Unfähigkeit, eine Wortbedeutung zu übersetzen, aufzeigen, den Mangel, der vielleicht in meiner Auswahl am augenfälligsten wurde ... Gegenwärtig endet, abgesehen von nicht sehr zufriedenstellenden Übersetzungsmethoden aus anderen Sprachen und einigen noch weniger zufriedenstellenden Versuchen mit kurzen Zusammenfassungen und Paraphrasen, diese Unterweisung in einem zu frühen Stadium. Bis jetzt ist noch kein Versuch gemacht worden, eine begründete allgemeine Interpretationstechnik darzulegen ... Welchen

Wert hat die Dichtung für Leser, die nicht herausfinden können, was sie bedeutet? $?^{3}$
Recursos pedagógicos concretos que poderiam levar a essa apreensão da realidade precisam primeiramente ser elaborados. Constituirá, certamente, um deles, o exercício de interpretação dramática de peças de teatro, a reflexão intensiva sobre obras literárias. Um componente desta formação consistiria em análises detalhadas das características internas e externas do herói, em descrições do local da ação e das situações, em análises precisas das relações entre personagens, entre ação e cenário, autor e obra, obra e tempo, em uma análise do reflexo de um lugar estranho na obra, em uma análise da ideia da obra, etc. Para desvendar significados textuais ocultos e desenvolver a fantasia do tradutor, seria possível buscar métodos semelhantes aos que Stanislávski utilizara na preparação de atores.

Conforme já mostravam as pesquisas de I. A. Richards do ano de 1929, uma grande parte dos leitores de literatura, principalmente de poesia, na verdade não entende o que lê:

... nós conseguimos provar a tão disseminada incapacidade de traduzir o significado de uma palavra, talvez a insuficiência mais evidente em minha seleção... Com exceção de métodos de tradução de outras línguas não muito satisfatórios e algumas pesquisas menos satisfatórias ainda, com pequenos resumos e paráfrases, esta instrução atualmente conclui-se em um estágio muito prematuro. Até agora não foi feita nenhuma pesquisa que mostrasse uma técnica racional de interpretação universal... Que valor tem a poesia para leitores que não conseguem descobrir o que ela significa? ${ }^{3}$

\footnotetext{
${ }^{3}$ I. A. RICHARDS, op.cit., 312-313.
} 
Obwohl die Praxis des close reading an amerikanischen und später auch an europäischen Universitäten in dieser Hinsicht bedeutende Fortschritte gemacht hat, zeigt sich gerade am Beispiel der Übersetzungen noch das denkerische Unvermögen und die Ungeschultheit auch unter vielen professionellen Lesern von Poesie.

\section{Die Interpretation der Vorlage}

Das wirklichkeitsbezogene Erfassen ist auch deshalb eine Voraussetzung für die künstlerische Beherrschung der Übersetzung, weil wegen der Inkongruenz des Sprachmaterials eine vollkommene Bedeutungsübereinstimmung im Ausdruck der Übersetzung und der Vorlage nicht möglich ist und daher eine nur sprachlich richtige Übersetzung nicht ausreicht. Es ist vielmehr eine Interpretation erforderlich. Oft tritt der Fall ein, daß die Muttersprache keinen in der Bedeutung so weiten und vielsagenden Ausdruck kennt, wie ihn die Vorlage benutzt. Dann muß der Übersetzer die Bedeutung spezifizieren und sich für eine der engeren Bedeutungen entscheiden. Hierzu muß er jedoch die Wirklichkeit kennen, die sich hinter dem Text verbirgt.

In Galsworthys Forsyte Saga ist eine der Gestalten gleich im ersten Kapitel als »the grave and foppishly determined Eustace« charakterisiert. Das englische Wort foppish hat mindestens zwei Grundbedeutungen, die Webster's Dictionary als foolish, stupid und foplike ... in dress or manners kennzeichnet. Da die Mehrzahl der Sprachen eines ähnlich doppeldeutigen Ausdrucks wie das englische foppish nicht fähig ist, muß der Übersetzer hier die Bedeutung einengen und damit interpretieren. Dies ist jedoch nur möglich, wenn er aus dem ganzen Roman eine klare Vorstellung von der Wirklichkeit gewonnen hat, in diesem Falle von dem Charakter des Eustace. Auf ähnliche Weise erfahren wir
Embora a prática do close reading em universidades americanas, e mais tarde também em europeias, tenha feito progressos significativos a este respeito, ainda se vê, tomando precisamente as traduções como exemplo, a incapacidade intelectual e o despreparo entre muitos leitores profissionais de poesia.

\section{A interpretação do modelo}

A apreensão baseada na realidade também é um prérequisito para o domínio artístico da tradução, pois, por conta da incongruência do material linguístico, uma perfeita harmonia de significados nas expressões da tradução e do modelo não é possível, de forma que uma tradução apenas linguisticamente correta não é suficiente. É obrigatória antes uma interpretação. Frequentemente ocorre o fato de a língua materna não possuir expressão com significado tão amplo e diverso quanto a utilizada no modelo. Nessa situação, o tradutor precisa especificar o significado e decidir-se por um dos significados mais estritos. Para tanto, ele deve, porém, conhecer a realidade que se oculta por trás do texto.

Na Forsyte Saga, de Galsworthy, um dos personagens é caracterizado logo no primeiro capítulo como "the grave and foppishly determined Eustace". A palavra inglesa foppish possui ao menos dois sentidos básicos assinalados pelo dicionário Webster's: foolish, stupid e foplike... in dress or manners. Visto que a maioria das línguas não possui uma expressão ambígua semelhante ao foppish do inglês, o tradutor precisa estreitar o significado, interpretando-o. Isto só é possível, contudo, se ele extrair, do romance no todo, uma ideia clara da realidade - neste caso, do conjunto de características de Eustace. De modo semelhante, logo na primeira frase sobre Eduard das Afinidades eletivas 
schon im ersten Satz von Goethes Wahlverwandtschaften über Eduard, daß er »im besten Mannesalter« stehe, und der englische übersetzer hat die Wahl zwischen in his prime und in early middle age. In jedem Text gibt es eine ganze Reihe von ähnlichen Situationen, in denen sich der Übersetzer zwischen mehreren möglichen Interpretationen entscheiden muß. Hierzu ein kleiner Ausschnitt aus Claudels Buch über Aristide Maillol:

Bourgade terrienne et maritime, Bayeuls sent la basse-cour et la marée ... A mi-hauteur du quartier de l'ouest, parmi la bousculade des cubes de maçonnerie crépis de blanc ou l'ocre, sur leurs toits de tuiles, une maison plus importante et mieux construite que les autres se détache, car elle est la seule qui soit rose, de ce joli rose cendré de soleil particulier au Midi.

Wie soll bourgade terrienne et maritime gedeutet werden als Hafen - und zugleich binnenländisches Städtchen oder als am Meer gelegener und innerer Teil der Stadt? Und wie soll man de ce joli rose cendré de soleil verstehen - geht es hier wirklich um eine angesengte, von der Sonne gebleichte rosa Farbe oder um eine optische Täuschung, d. h. um ein Rosa, das im blendenden Licht der südlichen Sonne für das ermüdete Auge an Intensität verliert?

Vom Originalautor verlangen wir die richtige Interpretation der Wirklichkeit, vom Übersetzer die richtige Interpretation der Vorlage. Im Zusammenhang damit sind drei Momente zu beachten:

a) das Suchen nach dem objektiven Sinn des Werks,

b) der Interpretationsstandpunkt des Übersetzers,

c) die Interpretation der objektiven Werte des Werks von diesem Standpunkt aus - die Konzeption des Übersetzers und die Möglichkeit einer Umwertung.
[Wahlverwandtschaften] de Goethe, ficamos sabendo que este se encontra "im besten Mannesalter", e o tradutor inglês tem de decidir entre "in his prime" e "in early middle age". Em todo texto há uma gama enorme de situações semelhantes, nas quais o tradutor precisa decidir-se entre diversas interpretações possíveis. A título de ilustração, um pequeno trecho do livro de Claudel sobre Aristide Maillol:

Bourgade terrienne et maritime, Bayeuls sent la basse-cour et la marée... A mi-hauteur du quartier de l'ouest, parmi la bousculade des cubes de maçonnerie crépis de blanc ou l'ocre, sur leurs toits de tuiles, une maison plus importante et mieux construite que les autres se détache, car elle est la seule qui soit rose, de ce joli rose cendré de soleil particulier au Midi.

Como deve ser interpretado "bourgade terrienne et maritime"? Como "cidadezinha portuária e terrestre" ou como "situado junto ao mar e na parte mais interna da cidade"? E como devemos entender de "ce joli rose cendré de soleil"? Trata-se aqui realmente de uma cor rosa desbotada pelo sol ou de uma ilusão de óptica, isto é, de um rosa que, para olhos cansados, perde a intensidade na luz ofuscante do sol meridional?

Do autor original exigimos a interpretação correta da realidade; do tradutor, a interpretação correta do modelo. Associados a essa exigência, devem ser observados três fatores:

a) a busca pelo sentido objetivo da obra,

b) o ponto de vista interpretativo do tradutor,

c) a interpretação dos valores objetivos da obra a partir deste ponto de vista - a concepção do tradutor e a possibilidade de uma revaloração. 
a) Aus dem, was über das Entstehen der Übersetzung gesagt wurde, geht hervor, daß jede Übersetzung eine mehr oder minder klare Interpretation darstellt. Soll die Interpretation richtig sein, so muß sie von den Wesenszügen des Werks ihren Ausgang nehmen und müssen die objektiven Werte des Werks ihr Ziel sein. Das Verhältnis des Künstlers zur Wirklichkeit charakterisiert L. I. Timofejev so:

Die charakteristische Eigenschaft der Vorstellungskraft eines wahren Künstlers ist jedoch neben ihrer Intensität und Stärke - ihre Uneigennützigkeit, genauer gesagt, ihre Objektivität, d. h. die Tatsache, daß der Künstler keineswegs von sich selbst träumt, sondern von der konkreten Welt, die ihn umgibt, daß er gleichsam eine >Seelenwanderung durchmacht $<$ und seinem Ich und seinen persönlichen Interessen entsagt ${ }^{4}$.

Das gleiche gilt auch für den Übersetzer. Seine Auffassung vom Werk wird nur dann realistisch sein, wenn er nicht schon als Leser einer billigen Sentimentalität und Ichbezogenheit verfällt. Jeder Leser macht häufig die Erfahrung, daß ihn die Gestalt eines Werks an jemanden erinnert, den er kennt, daß ihn Szenerien und Situationen an manche Ereignisse aus seinem eigenen Leben erinnern. Das Werk gerät für uns damit in eine Beziehung zu Wirklichkeiten, zu denen es objektiv überhaupt keine Verbindung hat. Der Leser projiziert seine persönliche Problematik in das Werk hinein. Diese Ichbezogenheit, dieser Subjektivismus des Lesers, ist eine der größten Klippen der Übersetzerarbeit, weil sie zu Lokalisierungen führen, die mit dem objektiven Sinn des Werks in Konflikt geraten. Es muß sich dabei nicht immer nur um die Einfügung von heimischen Realien oder von Anspielungen in den Text handeln. Eine weit unauffälligere, dabei aber wesentlichere a) Daquilo que foi dito sobre o modo como se origina a tradução, entende-se que toda tradução representa uma interpretação mais ou menos clara. Para que a interpretação esteja correta, ela precisa então ser proveniente das características da obra e os valores objetivos da obra devem ser sua meta. L. I. Timofeiev caracterizou a relação do artista com a realidade nos seguintes termos:

A propriedade peculiar da imaginação de um verdadeiro artista é - ao lado de sua intensidade e força - seu altruísmo; para dizer mais exatamente, sua objetividade, isto é, o fato de o artista em hipótese alguma sonhar consigo mesmo, mas sim com o mundo concreto ao seu redor, de praticamente sofrer uma 'transmigração da alma' e renunciar a seu Eu e seus interesses pessoais ${ }^{4}$.

O mesmo vale também para o tradutor. Sua compreensão da obra somente será realista se ele, mesmo como leitor, não se perder em sentimentalismo barato e egocentrismo. Todo leitor frequentemente tem a impressão de que o personagem de uma obra o faz lembrar-se de alguém que conhece; que cenários e situações o lembram de muitos eventos de sua própria vida. A obra nos faz estabelecer relações com realidades com as quais ela objetivamente não tem nenhuma ligação. $\mathrm{O}$ leitor projeta sua problemática pessoal na obra. Este egocentrismo, este subjetivismo do leitor é um dos maiores obstáculos ao trabalho do tradutor, pois estes levam a localizações que entram em conflito com o sentido objetivo da obra. Nem sempre se trata apenas de inserir dados da realidade local ou de alusões no texto. Uma outra forma de distorção menos chamativa, porém mais essencial, é a revaloração estilística, a inserção de qualidades estéticas na obra pelas

${ }^{4}$ L. I. TIMOFEJEV. Teorija literatury. Moscou, 1948, 33.

Scientia Traductionis, $n .11,2012$ 
Art der Verzerrung ist die stilistische Umwertung, das Einfügen ästhetischer Qualitäten in das Werk, für die zwar der Übersetzer eine Vorliebe hat, die jedoch im Original nicht enthalten sind. Das Ziel des Übersetzers sollte es sein, subjektive Eingriffe so weit wie möglich zu unterdrücken, damit er so der objektiven Gültigkeit des übersetzten Werks möglichst nahekommen kann.

Als Beispiel eines solchen Übersetzer-Subjektivismus kann Zschokkes Übersetzung von Molieres Précieuses ridicules angeführt werden, wo die Gestalten die persönlichen literarischen Sympathien und Antipathien des Übersetzers ausdrücken: Ursel ruft aus »Ah, den Oktavianus von Tieck- göttlich!«, Grethe fragt $»$ Kennen Sie auch Wieland und Voss?« und Johann antwortet »Wieland ist kein Dichter, und Voss ein längst vergessener alter Schmauch «.

Das angestrengte Suchen nach dem objektiven Kern und das Bemühen, ihm Ausdruck zu verleihen, kann man an der übersetzertätigkeit jedes bedeutenderen Klassikers verfolgen. Die antiästhetische Zivilisationspoesie Walt Whitmans z. B. fand erstmalig um das Jahr 1900 in die meisten europäischen Literaturen Eingang, in der Zeit der manirierten, parnassistischen und ästhetisierenden Poesie, und in dieser Zeit wurde so manche übersetzerische Lösung geschaffen, die sich bis heute behauptet hat, vor allem der Titel des Whitman'schen Zyklus selbst. Whitmans Werk wurde in Deutschland unter dem ästhetisierenden Titel Grashalme heimisch, obwohl leaves of grass Grasblätter bedeutet. Whitman selbst sprach sich gegen die englische Version Blades of Grass aus, eine Verbindung, die im Zusammenhang mit Gras im Englischen am häufigsten gebraucht wird, ebenso quais o tradutor tenha predileção, mas que, entretanto, não estão no original. O objetivo do tradutor deveria ser o de reprimir intervenções subjetivas tanto quanto possível, para conseguir aproximar-se o máximo da validade objetiva da obra traduzida.

Como exemplo de tal subjetivismo de tradutor, podemos mencionar a tradução que Zschokke fez das Précieuses ridicules de Molière, onde os personagens expressam as simpatias e antipatias literárias do tradutor: Ursel exclama: "Ah, den Oktavianus von Tieck, göttlich!", Grethe pergunta: "Kennen Sie auch Wieland und Voss?" e Johann responde: "Wieland ist kein Dichter, und Voss ein längst vergessene alter Schmauch".5

Pode-se observar na atividade do tradutor de todo clássico mais importante a busca obstinada pelo cerne objetivo e o esforço em dar-lhe expressão. A antiestética poesia de civilização de Walt Whitman, por exemplo, entrou pela primeira vez por volta de 1900 na maioria das literaturas europeias, em tempos de poesia de maneirismos, parnasiana e estetizante; e neste período foram criadas algumas soluções tradutórias que se impõem até hoje, começando com o próprio título de "ciclo whitmaniano". A obra de Whitman tornou-se conhecida na Alemanha sob o título estetizante de Grashalme, embora Leaves of Grass signifique Grasblätter. O próprio Whitman pronunciou-se contra a versão inglesa Blades of Grass, uma locução que com altíssima frequência é utilizada, em inglês, associada a grama, e também contra o mais poético Spears of Grass. Ele escolheu conscientemen-

\footnotetext{
${ }^{5}$ Ah, o Otavianus de Tieck, Deus meu!

Você também conhece Wieland e Voss?

Wieland não é poeta, e Voss uma velharia já há muito esquecida.
} 
gegen das poetischere Spears of Grass. Er wählte bewußt den weniger gebräuchlichen und weniger ansprechenden Titel Leaves of Grass, der vor allem den flachen, vom Stiel abstehenden Teil des Grases bezeichnet. Dem entspricht die weniger gebräuchliche und weniger ansprechende Benennung Grasblätter. Diese Bezeichnung war ein Bestandteil der antiästhetischen Orientierung der Poesie Whitmans, und es ist daher ein Verstoß gegen die Grundlagen seiner künstlerischen Absichten, wenn man den Titel in der ästhetisierenden Form übersetzt. (Ähnlich verhält es sich auch in einigen anderen Sprachen, z. B. im Tschechischen, wo der herkömmliche Begriff Stébla trávy (Grashalme) anstelle des richtigen Listy trávy (Grasblätter) gesetzt wird).

Im 6. Teil des Gesangs von mir selbst gibt Whitman eine Auslegung seines Symbols, und auch hier ist bei Lösung der Schlüsselpartien zu erkennen, wie die Übersetzer in dieser Dichtung ursprünglich Werte suchten, die programmatisch in ihr gar nicht enthalten sind:

A child said What is the grass? fetching it to me with full hands,

How could I answer the child? I do not know what it is any more than he.

I guess it must be the flag of my disposition, out of hopefull green stuff woven.

Or I guess it is the handkerchief of the Lord,

A scented gift and remembrancer designedly dropt,

Bearing the owner's name someway in the corners, that we may see and remark, and say Whose?

Or I guess the grass is itself a child, the produced babe of the vegetation.

Or I guess it is a uniform hieroglyphic,

And it means, Sprouting alike in broad zones and narrow zones,

Growing among black folks as among white,

Kanuck, Tuckahoe, Congressman, Cuff, I give them the same, I receive them the same. te o título menos utilizado e menos atrativo Leaves of Grass, que designa sobretudo a parte plana separada pelo talo da grama. A ele corresponde o termo menos utilizado e menos atrativo Grasblätter. Esta designação foi parte integrante da orientação antiestética da poesia de Whitman, e traduzir o título de forma estetizante é, portanto, uma violação contra as bases de seu propósito artístico. (Outras línguas comportam-se de forma semelhante. Por exemplo, no tcheco, onde o termo tradicional Stébla trávy ("hastes de grama") é empregado no lugar do correto Listy trávy ("folhas de grama").

Na Sexta Parte de Song of Myself, Whitman oferece uma interpretação de seu símbolo, e também nesse caso se pode identificar na solução de passagens decisivas o modo como os tradutores buscaram nesta poesia originariamente valores que do ponto de vista programático não estavam absolutamente contidos nela:

A child said What is the grass? fetching it to me with full hands,

How could I answer the child? I do not know what it is any more than he.

I guess it must be the flag of my disposition, out of hopefull green stuff woven.

Or I guess it is the handkerchief of the Lord,

A scented gift and remembrancer designedly dropt,

Bearing the owner's name someway in the corners, that we may see and remark, and say Whose?

Or I guess the grass is itself a child, the produced babe of the vegetation.

Or I guess it is a uniform hieroglyphic,

And it means, Sprouting alike in broad zones and narrow zones,

Growing among black folks as among white,

Kanuck, Tuckahoe, Congressman, Cuff, I give them the same, I receive them the same. 
Das Gras ist das Symbol für den Optimismus des Dichters (flag of my disposition ... hopeful green stuff), der bildliche Ausdruck des Geheimnisses der Natur (handkerchief of the Lord), der Jugend und der Geburt (babe of the vegetation) und des demokratischen Prinzips der Gleichheit aller Menschen (a uniform hieroglyphic... I give them the same, I receive them the same) und Träger der Vorstellung von der Regeneration (in weiteren, hier nicht zitierten Passagen).

Schlafs Übersetzung aus dem Jahre 1907 verrät durch eine Reihe von kleinen lexikalischen Verschiebungen, daß der Übersetzer im ganzen keine klare Vorstellung von der Symbolbedeutung des Bildes vom Gras hatte:

Ein Kind sagte: Was ist das Gras? und brachte es mir mit vollen Händen;

Wie konnte ich dem Kinde Antwort geben? Ich weiß es ebensowenig.

Ich meine, es müßte die Fahne meines Herzens sein, ganz aus einem hoffnungsgrünen Stoff gewoben.

Oder ich meine, es ist des lieben Gottes Taschentuch,

Eine duftige Gabe und ein Andenken, das mit Absicht fallen gelassen wurde,

Und das in irgendeinem Zipfel den Namen seines Eigners trägt, damit wir sehen, bemerken und sagen können: Wessen?

Oder ich meine, das Gras ist selbst ein Kind, ein von der Vegetation erzeugtes Kindlein.

Oder ich meine, es ist ein gleichförmiger Hieroglyph,

Und er bedeutet: ich sprieße so in weiten wie in engen Zonen;

Wachse bei schwarzen Völkern wie bei weißen, Kanuk, Tuckahoe, Kongreßmitglied, Boxer: alles beschenke ich, alle empfange ich aufs gleiche.

In die Reihe kleiner Ungenauigkeiten (disposition - Herz usw.) schlichen sich in die deutsche Whitman-Übersetzung traditionell-emotionale Motive ein. Ausgesprochen erotisch interpre-
A grama é o símbolo do otimismo do poeta ("the flag of my disposition" ... "hopeful green stuff"), a expressão imagética do mistério da natureza ("handkerchief of the Lord"), da juventude e do nascimento ("babe of the vegetation") e do princípio democrático da igualdade de todos os homens ("a uniform hieroglyphic"... "I give them the same, I receive them the same") e portadora da ideia de regeneração (em outras passagens não citadas aqui).

A tradução de Schlaf do ano de 1907 revela, por meio de uma série de pequenas modificações lexicais, que de modo geral o tradutor não tinha uma ideia clara do significado simbólico da imagem da grama:

Ein Kind sagte: Was ist das Gras? und brachte es mir mit vollen Händen;

Wie konnte ich dem Kinde Antwort geben? Ich weiß es ebensowenig.

Ich meine, es müßte die Fahne meines Herzens sein, ganz aus einem hoffnungsgrünen Stoff gewoben.

Oder ich meine, es ist des lieben Gottes Taschentuch,

Eine duftige Gabe und ein Andenken, das mit Absicht fallen gelassen wurde,

Und das in irgendeinem Zipfel den Namen seines Eigners trägt, damit wir sehen, bemerken und sagen können: Wessen?

Oder ich meine, das Gras ist selbst ein Kind, ein von der Vegetation erzeugtes Kindlein.

Oder ich meine, es ist ein gleichförmiger Hieroglyph,

Und er bedeutet: ich sprieße so in weiten wie in engen Zonen;

Wachse bei schwarzen Völkern wie bei weißen, Kanuk, Tuckahoe, Kongreßmitglied, Boxer: alles beschenke ich, alle empfange ich aufs gleiche.

$\mathrm{Na}$ série de pequenas imprecisões (disposition - Herzens, etc.), introduziram-se furtivamente, na tradução alemã de Whitman, motivos emotivos tradicionais. Um tradutor espanhol, em 
tierte das Gras-Symbol noch 1924 ein spanischer Übersetzer:

¿Qué es esto?, me dijo un niño mostrándome un puñado de hierba.

¿Qué podía yo reponderle?

yo no sé lo que es tampoco.

Tal vez es la bandera de mi amor, tejida con la sustancia

verde de la esperanza.

Tal vez es el pañuelo de Dios,

un regalo perfumado que alguien ha dejado caer

con alguna intención amorosa...

Dies steht in einem grundsätzlichen Gegensatz zur Poesie Walt Whitmans, in der bekanntlich das Fehlen erotischer Motive auffällt. Stattdessen herrscht bei ihm das Motiv der männlichen Solidarität vor.

Beinahe richtig übersetzt diese Schlüsselpartie bei Whitman erst 1922 Hans Reisiger ins Deutsche (wenn er auch durch irgendein Versehen die Reihenfolge der Motive durcheinanderwarf) :

Ein Kind sagte: $>$ Was ist das Gras? $<$ und pflückte es mir mit vollen Händen.

Wie konnt ich dem Kinde antworten? Ich weiß nicht besser, als das Kind, was es ist.

Ich glaube, es muß die Flagge meines Wesens sein, gewoben aus hoffnungsgrünem Stoff.

Oder vielleicht ist das Gras selber ein Kind, das Neugeborne der Pflanzenwelt.

Oder ich glaube, es ist das Taschentuch Gottes,

Eine duftende Gabe und Andenken, mit Absicht fallen gelassen,

Mit dem Namen des Eigentümers in einer der Ecken, so daß wir schauen und fragen mögen: $>$ Wem gehört's? $<$ usw.
1924, interpretou o símbolo da grama de uma forma marcadamente erótica:

¿Qué es esto?, me dijo un niño mostrándome un puñado de hierba.

¿Qué podía yo reponderle?

yo no sé lo que es tampoco.

Tal vez es la bandera de mi amor, tejida con la sustancia

verde de la esperanza.

Tal vez es el pañuelo de Dios,

un regalo perfumado que a1guien ha dejado caer

con alguna intención amorosa...

Isto está numa contradição fundamental com a poesia de Walt Whitman, na qual se evidencia, como bem se sabe, a falta de motivos eróticos. Predomina nele, ao contrário, o motivo da solidariedade masculina.

Uma tradução quase correta dessa passagem-chave de Whitman para o alemão é a realizada, somente em 1922, por Hans Reisiger (ainda que este, por uma distração qualquer, tenha embaralhado a sequência dos motivos).

Ein Kind sagte: 'Was ist das Gras?' und pflückte es mir mit vollen Händen.

Wie konnt ich dem Kinde antworten? Ich wei $\beta$ nicht besser, als das Kind, was es ist.

Ich glaube, es mu $\beta$ die Flagge meines Wesens sein, gewoben aus hoffnungsgrünem Stoff.

Oder vielleicht ist das Gras selber ein Kind, das Neugeborne der Pflanzenwelt.

Oder ich glaube, es ist das Taschentuch Gottes,

Eine duftende Gabe und Andenken, mit Absicht fallen gelassen,

Mit dem Namen des Eigentümers in einer der Ecken, so da $\beta$ wir schauen und fragen mögen: 'Wem gehört's?', etc. 
b) Entscheidend für die übersetzerische Konzeption ist der Interpretationstandpunkt. Entsprechend den apriorischen Grundsätzen, mit denen wir an ein Werk herantreten, und der Frage, was wir von ihm zu erwarten glauben oder was wir von ihm erwarten wollen, wird uns der Sinn vieler Werke auf verschiedene Weise offenbar werden:

Wenn man ein Gedicht nicht unter ästhetischen Gesichtspunkten betrachtet, kann es als geschichtliches Ereignis, als soziale Kritik, als diagnostischer Beweis für die Neurose des Autors gelten, und die Deutungsmöglichkeiten ließen sich noch in unbegrenzter Zahl erweitern ... Empedokles und Lukrez schrieben Philosophie. Nur in einem sehr entfernten Sinne des Wortes können wir sie Dichter nennen, obwohl ich nicht sagen möchte, daß Abschnitte ihrer Werke nicht als Dichtung gelesen werden können ... Und Juan de la Cruz - schrieb er eine Abhandlung über den Mystizismus oder ein Gedicht, als er EI cántico espiritual verfaßte? Die Antwort lautet, daß es darauf ankommt, wie es gelesen wird. Die Canciones entre el alma y el esposo von San Juan de la Cruz können als erotische Dichtung oder als ein Bericht über ein mystisches Erlebnis gelesen werden ... Für die Mehrzahl der Kritiker ist ein Romanschriftsteller bald ein Amateursoziologe, bald ein Moralist oder ein Theologe oder irgendetwas, was der Kritiker bei seinem unsystematischen Umherblättern zufällig im Schriftsteller entdeckt, indem er ihn liest, wie wir ein Referenzschreiben lesen. ${ }^{6}$

Im Gegensatz zum einfachen Leser, der mehr oder minder intuitiv dazu neigt, sich aus den Bestandteilen des Werks die intensivsten auszuwählen, bestimmt ein guter Übersetzer seinen Interpretationsstandpunkt meist bewußt, und er weiß, was er mit seiner Übersetzung dem Leser sagen will. Besonders ausgeprägt ist dieser Standpunkt bei den marxistischen Übersetzern: es geht darum, dem heimischen Leser so verständlich und dynamisch wie möglich besonders die Elemente des Werks zu ver- b) Decisivo para a concepção tradutória é o ponto de vista interpretativo. Dependendo dos fundamentos apriorísticos com os quais nos dirigirmos a uma obra, e da questão do que acreditamos esperar dela, ou queremos esperar dela, o sentido de muitas obras ficará claro para nós de maneira variada:

Se não se considera um poema sob pontos de vista estéticos, pode-se avaliá-lo como evento histórico, como crítica social, como prova diagnóstica da neurose do autor, e as possibilidades de interpretação ampliam-se ilimitadamente... Empédocles e Lucrécio escreviam filosofia. Somente em um sentido muito distante da palavra é que podemos chamá-los de poetas, embora eu não queira dizer que partes de suas obras não podem ser lidas como poesia... E Juan de la Cruz? Escreveu um tratado sobre o misticismo ou um poema, quando concebeu El cántico espiritual? A resposta é que depende de como é lido. As Canciones entre el alma y el esposo de San Juan de la Cruz podem ser lidas como poesia erótica ou como um relato sobre uma experiência mística... Para a maioria dos críticos, um escritor de romances é ora sociólogo amador, ora moralista ou um teólogo ou qualquer coisa que o crítico tenha descoberto casualmente no escritor em seu revirar assistemático de páginas, lendo-o como nós lemos uma carta de referência. ${ }^{6}$

Ao contrário do leitor comum, que de forma mais ou menos intuitiva tende a escolher dentre os componentes da obra aqueles mais intensos, um bom tradutor determina seu ponto de vista interpretativo na maioria das vezes de modo consciente, e sabe o que quer dizer ao leitor com sua tradução. Este ponto de vista é particularmente marcado nos tradutores marxistas: trata-se de traduzir ao leitor nacional tão inteligível e dinamicamente quanto possível principalmente os elementos da obra que expres-

${ }^{6}$ R. WELLEK. Confrontations. Yale UP, 1965, 224-226. 
dolmetschen, die direkt oder indirekt eine Sozialkritik aussprechen, die für eine materialistische Weltsicht und für eine realistische Denkweise zeugen. Als Beispiel für einen exklusiven und intellektuell übersteigerten Übersetzer-Standpunkt kann das Programm des amerikanischen Dichters Ezra Pound angeführt werden:

Schließlich ist es klar, daß der Übersetzer nicht für den sprachfaulen Leser alle Arbeit leisten kann. Er kann ihm zeigen, wo die Schätze verborgen liegen, er kann den Leser bei der Entscheidung leiten, welche Sprache er lernen solle, und kann dem Interessenten, der die fremde Sprache ein bißchen kennt und genügend Energie hat, um den Text des Originals parallel mit dem metrischen Kommentar zu lesen, ein erhebliches Maß an Zeit ersparen.

Im Einklang damit übersetzt er z. B. die altenglische Poesie nach der etymologischen Methode, d. h. er modernisiert die Wörter im lautlichen Sinne und setzt dann häufig in seine neuenglische Fassung etymologisch verwandte Wörter mit dem Ausdruckswert des Originals ein, die jedoch in ihrer Bedeutung weit von diesem entfernt sind. Im Gegensatz dazu geht der marxistische Übersetzer in erster Linie der Idee des Werks nach und paßt dieser die technischen Mittel an.

c) Aus der Ansicht über das Werk und aus der Blickrichtung auf einen bestimmten Leserkreis entsteht die Auffassung des Übersetzers von der Vorlage, die Übersetzerkonzeption, d. i. die ideelle Grundlage seiner Arbeitsmethode. Welchen Spielraum hat der Übersetzer bei der Interpretation des Werks? Es ist vielleicht nicht unlogisch, seiner Interpretation ähnliche Grenzen zu setzen wie der Interpretation des Literarhistorikers. Wenn sein sem direta ou indiretamente uma crítica social, que deponham em favor de uma visão de mundo materialista e uma mentalidade realista. Como exemplo de um ponto de vista do tradutor exclusivo e intelectualmente excessivo, pode-se citar o programa do poeta americano Ezra Pound:

Por fim, é evidente que o tradutor não pode realizar todo o trabalho para o leitor desatento ao próprio idioma. Ele pode mostrar-lhe onde os tesouros estão escondidos, pode encaminhar o leitor a tomar a decisão quanto a qual língua deve aprender e pode poupar um tempo considerável àquele interessado que conhece um pouco da língua estrangeira e possui energia suficiente para ler o texto original paralelamente com o comentário métrico.

Coerentemente com esse ponto de vista, ele traduz, por exemplo, a poesia em inglês antigo segundo o método etimológico, isto é, ele moderniza as palavras fonologicamente e muitas vezes emprega em sua versão em inglês moderno palavras etimologicamente semelhantes com o valor expressivo do original, que, contudo, possuem um significado distante deste. Diferentemente, o tradutor marxista segue sobretudo a ideia da obra e adapta a esta os recursos técnicos.

c) Da opinião sobre a obra e da orientação de um determinado círculo de leitores forma-se a compreensão do tradutor sobre o modelo, a "concepção do tradutor", isto é, a base ideacional de seu método de trabalho. Qual margem de manobra o tradutor possui na interpretação da obra? Talvez não seja ilógico estabelecer para a sua interpretação limites semelhantes aos da interpretação do historiador de literatura. Se seu objetivo não for uma

${ }^{7}$ Citado no volume On Translation. Harvar UP, 1958, 213.

Scientia Traductionis, $n .11,2012$ 
Ziel nicht eine literarische Spielerei ist, sondern das realistische Erfassen des Werks, dann muß die theoretische und künstlerische Deutung von den ideellen und ästhetischen Werten ausgehen, die im Werk, sei es sichtbar, sei es latent, enthalten sind. Er kann dem Werk nicht seine subjektiven Einfälle aufzwingen, doch kann er eine neue Sicht des Werks in die Wege leiten, indem er einen von dessen Aspekten enthüllt oder auf begründete Weise betont.

Während der Entstehungszeit war die Hauptidee von Shakespeares Was ihr wollt gegen seine wirtschaftlichen und politischen Gegner gerichtet - die Londoner Bürger, und geführt wurde der Angriff in Form einer Satire auf die Ideologie des Londoner Bürgertums, den Puritanismus. Dieser ideelle Gehalt ist für den heutigen Zuschauer ein totes historisches Faktum und wäre ihm nicht einmal jederzeit verständlich. Deswegen tritt in den heutigen Inszenierungen die gegen die konkrete historische Erscheinung gerichtete Satire in den Hintergrund - zugunsten einer allgemeineren positiven Idee: die Negation des Puritanismus bedeutet die Bejahung eines blutvollen Lebensoptimismus und der durch Viola verkörperten Jugend. Solch eine Konzeption kann auch als Grundlage der Auslegung durch den Übersetzer dienen. Der Übersetzer müßte in diesem Falle auf die Treue gegenüber den Einzelheiten, die mit Shakespeares Angriffen auf die Puritaner verbunden sind, keinen besonderen Nachdruck legen. Shakespeare z. B. ironisiert das Verbot der Puritaner, auf der Bühne den Namen Gottes auszusprechen, dadurch, daß er statt God absichtlich und an markanten Textstellen die Bezeichnung Jove (Jupiter), also den Namen einer bereits entthronten Gottheit, verwendet. Die Übersetzungen $» g e l o b t$ sei Jupiter und meine Sterne« und »Dank, Jupiter« haben für den heutigen Zuschauer keine ironische Bedeutung mehr. Es ist daher natürlich, wenn die brincadeira literária, mas sim a apreensão realista da obra, então a interpretação teórica e artística deve partir de valores ideacionais e estéticos que estejam contidos na obra, seja de modo visíveis, seja de modo latente. Ele não pode impor à obra suas ideias subjetivas, mas pode estabelecer uma nova visão da obra desvendando um de seus aspectos ou acentuando-o de maneira justificada.

Enquanto criava a Twelfth Night, Or What You Will, Shakespeare tinha como ideia principal dirigi-la contra seus adversários na economia e na política - os burgueses londrinos - e seu ataque foi realizado em forma de uma sátira da ideologia da burguesia londrina, o puritanismo. Esse conteúdo ideacional é, para o público atual, um fato histórico acabado e pode não ser compreensível para ele nem mesmo a todo instante. Por isso, nas encenações atuais, a sátira dirigida contra o acontecimento histórico concreto passa para segundo plano - em favor de uma ideia positiva mais geral: a negação do puritanismo significa a afirmação de um intenso otimismo perante a vida e da juventude personificada por Viola. Tal concepção também pode servir como fundamento da interpretação pelo tradutor. O tradutor, neste caso, não precisaria dar especial ênfase à fidelidade para com os detalhes ligados aos ataques de Shakespeare contra os puritanos. Shakespeare, por exemplo, ironiza a proibição dos puritanos de se pronunciar o nome de Deus no palco, utilizando, intencionalmente, em vez de God, e em passagens relevantes a denominação Jove (Júpiter) - portanto, o nome de uma divindade já destronada. As traduções "gelobt sei Jupiter und meine Sterne" e "Dank, Jupiter", não têm mais, para o público de hoje, nenhum sentido irônico. É, assim, natural que os tradutores utilizem os correntes termos Götter (Schlegel) e Himmel (Dingelstedt), entre outros. O 
Übersetzer das geläufige "Götter« (Schlegel), "Himmel« (Dingelstedt) u. ä. verwenden. Ebenso verhält es sich bei den Anspielungen auf die Meineidigkeit der Katholiken und an anderen Stellen.

Verschiebungen in der Auffassung sind nur in den Grenzen möglich, die durch den realen und potentiellen Gehalt eines Werks gegeben sind. Man kann weder theoretisch noch künstlerisch eine übersetzerische Interpretation verteidigen, die in das Werk heterogene, der objektiven Idee widersprechende Elemente einführt. Wenn der Übersetzer in seiner Arbeit die eigene Idee gegenüber der Idee des Werks durchsetzt, dann überdeckt er die ursprüngliche Bedeutung mit einer neuen Interpretation und schafft eine Allegorie.

Der Übersetzer kann selten auf eine erfolgreiche Polemik mit dem Original hoffen, denn hierzu müßte er der fremden Poetik eine eigene gegenüberstellen, die zudem noch dem Thema angemessen sein müßte. Manchmal gelingt es nur, das Original seines spezifischen Stils zu berauben und den Inhalt in einer neutralen Mitteilungssprache wiederzugeben. Um eine Polemik mit Verlaines Gedicht Le Rossignol (Die Nachtigall) bemühte sich 1930 Georg von der Vring:

Comme un vol criard d'oiseaux en émoi,

Tous mes souvenirs s'abattent sur moi,

S'abattent parmi le feuillage jaune

De mon coeur mirant son tronc plié d'aune

Au teint violet de l'eau des Regrets,

Qui mélancoliquement coule auprès,

S'abattent, et puis la rumeur mauvaise

Qu'une brise moite en montant apaise,

S'éteint par degrés dans l'arbre, si bien

Qu'au bout d'un instant on n'entend plus rien,

Plus rien que la voix célébrant l' Absente,

Plus rien que la voix - ô si languissante! mesmo acontece com as alusões a perjúrio dos católicos e em outras passagens.

Modificações na compreensão são possíveis somente nos limites estabelecidos pelo conteúdo real e potencial de uma obra. Não se pode defender, nem teórica nem artisticamente, uma interpretação tradutória que introduza na obra elementos heterogêneos, que contrariem a ideia objetiva. Se o tradutor, em seu trabalho, impuser a própria ideia contra a ideia da obra, estará encobrindo o sentido original com uma nova interpretação e criando, assim, uma alegoria.

O tradutor raramente pode confiar numa polêmica bemsucedida com o original, pois para tanto teria que opor à poética alheia uma própria, que, ademais, ainda teria que ser adequada ao tema. Às vezes, consegue apenas privar o original de seu estilo específico e reproduzir o conteúdo em uma linguagem de comunicação neutra. Em 1930, Georg von der Vring esforçou-se por uma polêmica com o poema "Le Rossignol" ["O rouxinol"], de Verlaine:

Comme un vol criard d'oiseaux en émoi,

Tous mes souvenirs s'abattent sur moi,

S'abattent parmi le feuillage jaune

De mon coeur mirant son tronc plié d'aune

Au teint violet de l'eau des Regrets,

Qui mélancoliquement coule auprès,

S'abattent, et puis la rumeur mauvaise

Qu'une brise moite en montant apaise,

S'éteint par degrés dans l'arbre, si bien

Qu'au bout d'un instant on n'entend plus rien,

Plus rien que la voix célébrant l'Absente,

Plus rien que la voix - ô si languissante! 
De l'oiseau qui fut mon Premier Amour,

Et qui chante encore comme au premier jour;

Et, dans la splendeur triste d'une lune

Se levant blafarde et solenelle, une

Nuit mélancolique et lourde d'été,

Pleine de silence et d'obscurité,

Berce sur l'azur qu'un vent effleure

L'arbre qui frissonne et l'oiseau qui pleure.

Wie ein Schwarm schreiender Vögel

Stürzen sich die Erinnerungen

Unter das gelbe Laub meines Lebensbaumes,

Dessen gebeugter Stamm sich spiegelt

Im bitteren Bache der Reue -

Stürzen sich lärmend -

Bis sie im schlaffen Winde hinsterben,

Verstummen - und nichts mehr tönt

Als die feierliche Stimme, o deine!

Nichts als die schmachtende arme

Stimme des Vogels, Stimme meiner ersten

Und unaustilglichen Liebe -

Tönt

Im trüben Mond,

Welcher steigt durch die schwere

Stumme Nacht auf und schwebt

Und im Wind,

Welcher anrührt meinen fröstelnden Baum

Und darin

Den schluchzenden Vogel.

In der deutschen Version wurde das Gedicht um etwa die Hälfte gekürzt (im Original 171, in der übersetzung 86 Wörter), indem die Stilmittel des französischen Fin de siècle getilgt wurden: das Gedicht beginnt mit dem die Bedeutung vernebelnden und klanglich melodisierenden Reim en émoi sur moi, dem Motiv des spiegelnden Herzens, der violetten
De l'oiseau qui fut mon Premier Amour,

Et qui chante encor comme au premier jour;

Et, dans la splendeur triste d'une lune

Se levant blafarde et solennelle, une

Nuit mélancolique et lourde d'été,

Pleine de silence et d'obscurité,

Berce sur l'azur qu'un vent doux effleure

L'arbre qui frissonne et l'oiseau qui pleure.

Wie ein schwarm schreiender Vögel

Stürzen sich die Erinnerungen

Unter das gelbe Laub meines Lebensbaumes,

Dessen gebeugter Stamm sich spiegelt

Im bitteren Bache der Reue -

Stürtzen sich lärmend -

Bis sie im schlaffen Winde hinsterben,

Verstummen - und nichts mehr tönt

Als die feierliche Stimme, o deine!

Nichts als die schmachtende arme

Stimme des Vogels, Stimme meiner ersten

Und unaustilglichen Liebe -

Tönt

Im trüben Mond,

Welcher steigt durch die schwere

Stumme Nacht auf und schwebt -

Und im Wind,

Welcher anrührt meinen fröstelnden Baum

Und darin

Den schluchzenden Vogel.

$\mathrm{Na}$ versão alemã, a poesia foi encurtada aproximadamente pela metade (no original, 171 palavras; na tradução, 86), apagando os recursos estilísticos do fin de siècle francês: o poema inicia com a rima sonoramente melodiosa e que torna nebuloso o sentido, "en émoi" - "sur moi", com o motivo do coração espelhado, com o matiz violáceo da água simbólica, etc. A redução dos ale- 
Schattierung des symbolischen Wassers usw. Der Umstilisierung in ein modernes Gedicht kommt auch die Kürzung des Alexandriners der Vorlage in freie Verse von ungleicher Länge entgegen. Aber auch nach einer solch konsequenten Umformung bleibt das Gedicht mit seinem ganzen motivischen Aufbau dem 19. Jahrhundert verbunden: die Nachtigall, der Lebensbaum, der bittere Bach der Reue, feierliche Stimme, schmachtende Stimme, der trübe Mond, stumme Nacht, der schluchzende Vogel usw. Es entstand also keine zeitgenössische Dichtung, sondern eher ein Resümee, in das die eine Seite der Poetik der Vorlage nicht mit einbezogen wurde. Der Übersetzer bezeichnete diesen Versuch mit Recht als Skizze.

Mehrerlei grundverschiedene Auffassungen, somit auch übersetzerische Konzeptionen, sind nur bei einigen der ältesten Texte möglich, besonders bei solchen, in denen der wörtlichen Bedeutung Symbolwerte übergeordnet sind, wie bei der christlichen Bibel, der altindischen oder der chinesischen taoistischen Literatur.

In einer Literatur, in der es keine Zweifel über die Interpretation gibt, ist die Möglichkeit einer zweifachen Auslegung auf bedeutungslose Einzelheiten beschränkt, und auch die stilistische Überbewertung hat ihre Grenzen, die durch die Idee und den Stil des Originals gegeben sind. Die Mittel, mit denen der Übersetzer seine Konzeption durchsetzen kann, sind begrenzt und doch wirksam. Durch stilistische Modifikationen zwingt faktisch jeder Übersetzer, und besonders der Übersetzer von Poesie, dem Original in mehr oder minder starkem Maße seinen Stil und damit auch seine Auffassung vom Werk auf. Freilich darf die stilistische Umwertung nicht so weit gehen, daß sie den Sinn des Originals verzeichnet. Und vor allem sollte der Übersetzer weder seine ideelle, noch seine künstlerische Konzeption durch Eingriffe in den Text, durch Kürzungen oder Ergänzungen des Origi- xandrinos do modelo em versos livres, de comprimentos desiguais, vai ao encontro da transformação do estilo para um poema moderno. Mas mesmo depois de uma tal coerente transformação, o poema permanece comprometido com toda a sua estrutura motívica do século 19: o rouxinol, a árvore da vida, o amargo arroio do remorso, a voz solene e lânguida, a lua sombria, a noite silenciosa, o pássaro lamuriento, etc. Não surgiu, portanto, uma poesia contemporânea, mas antes um resumo, no qual uma face da poética do modelo não foi incluída. Com razão, o tradutor chamou esse experimento de esboço.

Numerosas e absolutamente distintas compreensões e, consequentemente, concepções tradutórias também, só são possíveis em alguns dos textos mais antigos, principalmente naqueles em que os valores simbólicos estão colocados acima do significado literal, como na Bíblia cristã, na literatura indiana antiga ou na chinesa taoísta.

Em uma literatura na qual não há dúvidas quanto à interpretação, a possibilidade de uma dupla exegese está limitada a detalhes insignificantes, e também a supervalorização estilística tem seus limites, que são estabelecidos pela ideia e estilo do original. Os meios pelos quais o tradutor pode introduzir sua concepção são limitados, porém eficazes. Através de modificações estilísticas, de fato todo tradutor, e principalmente o tradutor de poesia, impõe ao original, em maior ou menor escala, o seu estilo e, com isso, a sua compreensão da obra. Todavia, a revaloração estilística não pode ser tão ampla que desfigure o sentido do original. E, sobretudo, o tradutor não deveria introduzir nem suas ideias nem sua concepção artística por meio de intervenções no texto, de reduções ou complementações do original. Isso não seria mais uma tradução, mas sim um arranjo, e todo arranjo de- 
nals, durchsetzen wollen. Dies nämlich wäre keine Übersetzung mehr, sondern ein Arrangement, und jedes Arrangement entstellt ein Kunstwerk.

\section{Die Umsetzung der Vorlage}

Vom Originalautor verlangen wir eine künstlerisch gültige Darstellung der Wirklichkeit - vom Übersetzer verlangen wir eine künstlerisch gültige Umformulierung der Vorlage. Sein Talent kann der Übersetzer vor allem bei der sprachlichen Fassung zur Geltung bringen; deshalb braucht er in erster Linie Stilgefühl. Die sprachliche Problematik des Übersetzens erstreckt sich besonders auf folgende Fragen:

a) das Verhältnis der beiden Sprachsysteme zueinander,

b) die Spuren der Originalsprache in der Übersetzung,

c) das Spannungsverhältnis im Stil der Übersetzung, das dadurch entsteht, daß ein Gedanke in eine Sprache transponiert wird, in der er nicht entstanden ist.

a) Die Sprache der Vorlage und die Sprache der Übersetzung sind nicht auf geradlinige Weise miteinander vergleichbar. Die sprachlichen Mittel bei der Systeme sind nicht gleichwertig, und deshalb darf nicht mechanisch übersetzt werden. Die Bedeutungen und deren ästhetischen Werte decken sich nicht genau. Daher ist die Übersetzung umso schwieriger, je größer die Rolle der Sprache bei der künstlerischen Gestaltung des Textes ist. So sind bei der Übersetzung von Poesie eine besonders große Wendigkeit und eine auf das Ganze bezogene größere Freiheit erforderlich. forma uma obra de arte.

\section{A transposição do modelo}

Do autor original exigimos uma representação artisticamente válida da realidade; do tradutor exigimos uma reformulação artisticamente válida do modelo. O tradutor pode fazer valer seu talento sobretudo na versão linguística; para tanto, necessita, em primeiro lugar, sensibilidade para o estilo. A problemática linguística do traduzir estende-se principalmente às seguintes questões:

a) a relação de ambos os sistemas linguísticos entre si,

b) os vestígios da língua original na tradução,

c) a relação de tensão no estilo da tradução, que surge na medida em que um pensamento é transposto para uma língua na qual ele não foi gerado.

a) A língua do modelo e a língua da tradução não são linearmente comparáveis entre si. Os recursos linguísticos de ambos os sistemas não são equivalentes e, por isso, não podem ser traduzidos maquinalmente. Os significados e seus valores estéticos não se cobrem com exatidão. Eis por que a tradução é tanto mais difícil quanto maior for o papel da língua na configuração artística do texto. Assim, na tradução de poesia são requeridas uma versatilidade especialmente grande e uma maior liberdade em relação ao todo. 
Man kann die Inkongruenz zweier Sprachmaterialien in formaler Beziehung und die Gewaltanwendung, die deshalb besonders in der Poesie an Sprache und Inhalt eines Werks notwendig wird, fast mit mathematischer Exaktheit demonstrieren. Stellen wir einige Sätze aus Romain Rollands Roman Colas Breugnon im Original und in der deutschen Übersetzung gegenüber:

Saint Martin soit béni. / Les affaires ne vont plus. / Inutile de s'éreinter. / J'ai assez travaillé / dans ma vie. / Prenons un peu de bon temps. / Me voici à ma table, / un pot de vin à ma droite, / l'encrier à ma gauche; / un beau cahier tout neuf, / devant moi, / m'ouvre ses bras. / A ta santé, mon fils, / et causons! / En bas, ma femme tempête.

$(6-6-7-6+3-7-7-7-6-6+3-4-6+3-6=83$ Silben in 15 Abschnitten).

Gelobt sei der heilige Martinus. / Mit den Geschäften ist es aus und vorbei. / Ein eitles Tun wär's, / sich noch weiter abzurackern. / Ich habe in meinem Leben genugsam gearbeitet. I Jetzo will ich mir's ein wenig wohl sein lassen. / Da sitze ich an meinem Tische nieder, / rechts einen Humpen Wein, / links das Tintenfaß. / Vor mir liegt ein gar schönes neues Heft, / das mir zum Schreiben winket. / Zum Wohl, alter Junge, / nun laß uns schwatzen! / Unten belfert meine Frau.

$(10-11-5-8-8+7-5-7-11-6-6-10-7-7-5-7=$ 119 Silben in 16 Abschnitten).
Pode-se demonstrar quase com exatidão matemática a incongruência entre dois materiais linguísticos quanto à forma e o uso da força - que justamente em razão daquela se torna necessário principalmente na poesia - sobre a língua e o conteúdo de uma obra. Contrastemos algumas sentenças do romance Colas Breugnon, de Romain Rolland, no original e na tradução alemã:

Saint Martin soit béni. / Les affaires ne vont plus. / Inutile de s'éreinter. / J'ai assez travaillé / dans ma vie. / Prenons un peu de bon temps. / Me voici à ma table, / un pot de vin à ma droite, / l'encrier à ma gauche; / un beau cahier tout neuf, / devant moi, / m'ouvre ses bras. / A ta santé, mon fils, / et causons! / En bas, ma femme tempête.

$(6-6-7-6+3-7-7-7-6-6+3-4-6+3-6=83$ sílabas em 15 segmentos).

Gelobt sei der heilige Martinus. / Mit den Geschäften ist es aus und vorbei. / Ein eitles Tun wär's, / sich noch weiter abzurackern. / Ich habe in meinem Leben genugsam gearbeitet. $I$ Jetzo will ich mir's ein wenig wohl sein lassen. / Da sitze ich an meinem Tische nieder, / rechts einen Humpen Wein, / links das Tintenfaß. / Vor mir liegt ein gar schönes neues Heft, / das mir zum Schreiben winket. / Zum Wohl, alter Junge, / nun laß uns schwatzen! / Unten belfert meine Frau. $^{8}$

$(10-11-5-8-8+7-5-7-11-6-6-10-7-7-5-7=$ 119 sílabas em 16 segmentos).

${ }^{8}$ Bendito seja São Martinho./Com os trabalhos está tudo acabado./Uma vã empresa seria/ esforçar-se ainda mais. /Eu tenho trabalhado, em minha vida, suficientemente./Agora quero me deixar estar um pouco./ Sento-me à mesa, /à direita, um cálice de vinho, /à esquerda, o pote de tinta. / Diante de mim, um novo caderno/ que me acena para escrever. / Saúde, meu filho, /agora vamos conversar!/ Embaixo, minha mulher esbraveja. N. do T. 
Die Gedanken des Rolland'schen Romans sind in kurzen Sätzen oder Satzabschnitten formuliert, die meist 6-7 Silben umfassen. Bei solch konsequenter Regelmäßigkeit entsteht ein ganz bestimmter rhythmischer Eindruck. Die entsprechenden deutschen Abschnitte sind länger (durchschnittlich 7,4 gegenüber 5,5 im französischen Text), da die Wortlänge im Deutschen größer ist als im Französischen und da es sich häufig um eine paraphrasierende Ausdrucksweise handelt: lnutile de s'éreinter - Ein eitles Tun wär's, sich noch weiter abzurackern. Entscheidend ist jedoch, daß die deutschen Abschnitte verschieden lang sind (5-11 Silben), weil sie den Inhalt der Vorlage erfassen müssen, während im Original die Sprache den Textumfang der formulierten Gedanken mitbestimmt hat. Dadurch, daß sich in der neuen Sprache das Verhältnis zwischen dem Gedanken und dem Silbenumfang seiner Außerung veränderte, wurde die rhythmische Einleitung des Romans gestört. Hätte übrigens der Rhythmus in dem Prosaabsatz von Rolland für den deutschen Leser die gleiche ästhetische Gültigkeit wie für den französischen Leser, wenn es Erna Grautoff gelungen wäre, ihn streng einzuhalten? Für das französische rhythmische Empfinden ist der 6-7-silbige Abschnitt eine grundlegende und fest eingebürgerte rhythmische Einheit: er bildet die Hälfte des 12-13-silbigen Alexandriners, der durch die Zäsur verbindlich in zwei Halbverse geteilt wird. In der deutschen rhythmischen Tradition hat er eine ganz andere Bedeutung. In seiner Gültigkeit nähert sich dem Halbvers des französischen Alexandriners vielleicht der deutsche 10- oder 5silbige Abschnitt (d. i. der Blankvers oder dessen Hälfte), zu dem die Übersetzung schon aus sprachlichen Gründen selbständig tendiert.
As ideias do romance de Rolland estão formuladas em frases curtas ou segmentos frasais que contêm, em sua maioria, de 6 a 7 sílabas. Desta regularidade coerente, resulta uma impressão rítmica bem definida. As divisões correspondentes em alemão são mais longas (em média, 7,4 contra 5,5 no texto francês), visto que o comprimento das palavras no alemão é maior do que no francês, e que se trata frequentemente de um modo de expressão parafraseante: "Inutile de s'éreinter" - "Ein eitles Tun wär's, sich noch weiter abzurackern". Contudo, é decisivo que os segmentos em alemão sejam de tamanhos diferentes (5-11 sílabas), porque estes devem apreender o conteúdo do modelo, enquanto no original, a língua codeterminou o volume de texto das ideias formuladas. Por ter se alterado, na nova língua, a relação entre a ideia e a quantidade de sílabas a expressá-la, prejudicou-se a disposição rítmica inicial do romance. A propósito, teria o ritmo dos parágrafos da prosa de Rolland para o leitor alemão a mesma validade estética que tem para o leitor francês, se Erna Grautoff tivesse conseguido mantê-lo rigorosamente? Para a sensibilidade rítmica do francês, a separação em 6-7 sílabas é uma unidade rítmica fundamental e que se naturalizou francesa definitivamente: ela constitui a metade das 12-13 silabas do alexandrino, que é obrigatoriamente dividido pela cesura em dois hemistíquios. Na tradição rítmica alemã, este possui um significado completamente diferente. Em termos de validade, talvez o que se aproxima do hemistíquio do alexandrino francês seja o segmento alemão de 10 ou 5 sílabas (isto é, o verso branco ou sua metade), para o qual a tradução tende independentemente até mesmo por razões linguísticas. 
Noch markanter ist freilich die Inkongruenz der Sprachen in semantischer Beziehung. Die uns umgebende Wirklichkeit ist ein Kontinuum, das der Sprechende in Segmente gliedert, denen er Namen gibt. Diese Gliederung folgt teilweise der Struktur der Wirklichkeit und ist teilweise durch das Benennungssystem der gegebenen Sprache der Wirklichkeit übergeordnet: ein Haus hat beispielsweise ganz offenkundig seine Struktur, die aus den Elementen Dach, Fenster, Treppenhaus, Stockwerk usw. besteht. Aber nur einige europäische Sprachen unterscheiden bei den Treppen flights of stairs und landings und bei der Bezeichnung der Stockwerke gelten verschiedene Perspektiven: Amerikaner und Russen zählen die Stockwerke von der Erdoberfläche, die Deutschen schließen das Erdgeschoß aus und zählen erst vom nächsten Stockwerk die erste Etage usw. Besonders deutlich sind die Unterschiede etwa bei der Farbenskala oder der Einteilung der Tageszeiten (und damit im Zusammenhang der täglichen Mahlzeiten) :

\begin{tabular}{|c|c|c|c|c|c|c|c|}
\hline Nacht & Morgen & Vormittag & Nachmittag & $\mathrm{Abe}$ & & $\mathrm{Nacl}$ & \\
\hline $\begin{array}{ll}0 & 2 \\
\end{array}$ & $\begin{array}{lll}4 & 6 & 8 \\
\end{array}$ & $\begin{array}{ll}10 & 12 \\
\end{array}$ & $14 \quad 16$ & 18 & 20 & 22 & 24 \\
\hline
\end{tabular}

In den einzelnen ethnischen Bereichen gibt es große Unterschiede bei der Bezeichnung verschiedener Typen und Grade verwandtschaftlicher Beziehungen: als Beispiel führen wir nur einen kleinen Ausschnitt aus dem System dieser Verwandtschaftsbezeichnungen an:
Ainda mais marcante é, sem dúvida, a incongruência das línguas do ponto de vista semântico. A realidade que nos rodeia é um continuum que o falante divide em segmentos para os quais dá nomes. Esta classificação segue em parte a estrutura da realidade e em parte está hierarquicamente posta acima da realidade pelo sistema de nomenclatura da língua dada: por exemplo, uma casa possui de maneira bem manifesta sua estrutura, que é composta de elementos como telhado, janela, escadaria, pisos, etc Mas somente algumas línguas europeias distinguem, no que se refere às escadas, entre flights of stairs e landings e tratam a designação dos andares sob diferentes perspectivas: americanos e russos contam os pisos a partir do solo, os alemães excluem o térreo e contam somente o próximo piso como primeiro andar, etc. Bastante claras são as diferenças acerca da escala de cores ou da divisão dos períodos do dia (e, consequentemente, das refeições diárias):

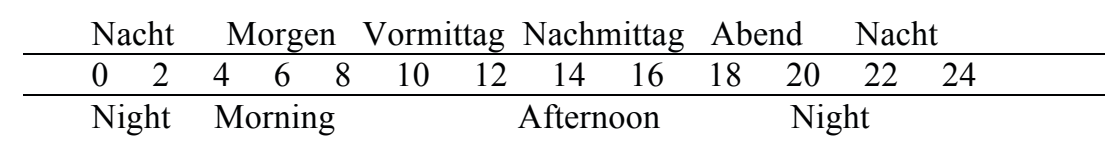

Em cada um dos variados campos étnicos, há grandes diferenças na designação dos diferentes tipos e graus das relações de parentesco. Para exemplificar, apresentamos um pequeno segmento do sistema dessas designações de parentesco: 


\begin{tabular}{l|l|l|l|l} 
& Ungarish & Englisch & Deutsch & Indonesisch $^{9}$ \\
\hline Älterer Bruder & Batya & brother & Bruder & \\
\hline Jüngerer Bruder & öccs & & Geschwister & Sudara \\
\hline Älterer Schwester & nene & sister & Schwester & \\
\hline Jüngerer Schwester & nug & & &
\end{tabular}

Die unterschiedliche Segmentierung der Wirklichkeit äußert sich begreiflicherweise $u$. a. auch in den poetischen Bildern: stellen wir uns z. B. eine Übersetzung der Poesie Georg Trakls in eine Sprache vor, die keine genügende Auswahl von Bezeichnungen für die rote Farbe aufweist, oder eine Übersetzung Shelleys in eine Sprache, die kein Empfinden für den Gegensatz zwischen dunklen und hellen Schattierungen hat.

Zusammenfassend kann gesagt werden, daß der Wortschatz der verschiedenen Sprachen eine unterschiedliche Anzahl von Begriffen zur Bezeichnung der einzelnen Gebiete der Wirklichkeit aufweist.

Selbst ein sehr einfaches Beispiel für die sprachliche Anordnung des Textes konnte zeigen, daß letztlich auch eine gute Übersetzung ein Kompromiß ist. Der Charakter und die Gestalt des Gedankens im Originalwerk, deren Folge und Anlage, sind zu einem großen Teil von den syntaktischen Möglichkeiten und von dem Vorrat an Benennungen abhängig, die der Originalsprache zur Verfügung stehen.

Für den Bedarf der Übersetzer würden wir für die einzelnen Sprachpaare vergleichende Stilistiken benötigen, die von der Voraussetzung ausgingen, daß die einzelnen Sprachen Mitteilungssysteme sind, die (dies gilt zumindest für die europäischen Sprachen) durch die Gesamtheit ihrer Mittel im großen Ganzen die gleichen Informationen vermitteln können.

\footnotetext{
${ }^{9}$ Cf. Revzin-Rozencvejg, op.cit., 50.
}

\begin{tabular}{l|l|l|l|l} 
& Húngaro & Inglês & Alemão & Indonésio $^{9}$ \\
\hline Irmão mais velho & Batya & brother & Bruder & \\
\hline Irmão mais novo & öccs & & Geschwister & Sudara \\
\hline Irmã mais velha & nene & sister & Schwester & \\
\hline Irmã mais nova & nug & & &
\end{tabular}

A diferenciada segmentação da realidade naturalmente também se manifesta nas imagens poéticas: imaginemos, por exemplo, uma tradução da poesia de Georg Trakl para uma língua que não apresente variedade suficiente de denominações para a cor vermelha, ou uma tradução de Shelley para uma língua que não possua percepção em relação ao contraste entre matizes escuros e claros.

Em resumo, pode-se dizer que o vocabulário das diferentes línguas traz um número variável de termos para designar os diferentes âmbitos da realidade.

Mesmo um exemplo muito simples no arranjo linguístico do texto poderia mostrar que uma boa tradução também é fundamentalmente um acordo. O caráter e a forma do pensamento na obra original, sua ordem e disposição, são dependentes, em grande medida, das possibilidades sintáticas e do repertório de denominações que estejam à disposição da língua original.

Para as necessidades dos tradutores, precisaríamos de estilísticas comparadas para cada par de línguas, as quais partiriam da hipótese de que as línguas em si são sistemas de comunicação que através do conjunto de seus recursos conseguem, em geral, transmitir as mesmas informações (isto vale pelo menos para as línguas europeias). De uma comparação entre dois sistemas lin- 
Aus einem Vergleich zweier Sprachsysteme würde dann hervorgehen A) welche Informationsmittel der beiden Sprachen man ungefähr als gleichwertig ansehen kann, B) welche Informationsmittel der Ausgangssprache in der Zielsprache fehlen und C) welche Informationsmittel dagegen die Sprache der Übersetzung zusätzlich hat.

In den Fällen des Typs B müssen die Mittel der Zielsprache kompensiert werden - und gerade um dieser Kompensation willen muß man beide Sprachen als Systeme betrachten, in denen gewöhnlich die Abschwächung einer Kategorie von Bedeutungsmöglichkeiten durch eine reich entwickelte andere Kategorie ausgeglichen wird.

Die westeuropäismen Sprachen haben eine reich differenzierte Kategorie der Zeit bei den Verben, die Mehrzahl der slavischen Sprachen hingegen besitzt die zusätzliche Kategorie der Aspekte. Die Handlungsfolge, die ein westeuropäischer Originaltext mit 6-8 Tempora präzisieren kann, muß die slavische Übersetzung in der Regel mit 3 Tempora erfassen; die fehlenden Zeiten kompensiert sie durch die Anwendung von Aspektvorsilben oder Zeitadverbien. In ähnlichem Sinne muß man auch lexikalisme und stilistische Mittel kompensieren. Das Englische und das Russische haben den Vorteil, aus jeweils zwei verschiedenen lexikalischen Schichten zu bestehen (der romanischen und der germanischen, der kirchenslavischen und der russischen), die slavischen Sprachen sind überdies reich an Wörtern mit vielfältigen Gefühlsschattierungen, von verkleinernden Koseformen bis zu ironisierenden Abwandlungen. Dem Deutschen geben seine zusammengesetzten Wörter und der Austausch der Präfixe spezifische Möglichkeiten. Die slavischen Sprachen können die Bedeutungen durch Präfixe, Suffixe und durch Veränderungen der Wortwurzel fein nuancieren. guísticos depreender-se-ia então: A) quais recursos de informação de ambas as línguas podem ser considerados praticamente equivalentes; B) quais recursos de informação da língua de partida faltam na língua de chegada; e C) quais recursos de informação, por outro lado, a língua da tradução possui a mais.

Nos casos do tipo B, os recursos da língua de chegada devem ser compensados - e justamente por causa desta compensação devem-se considerar ambas as línguas como sistemas nos quais geralmente o enfraquecimento de uma categoria de possibilidades de significado é compensada por uma outra categoria ricamente desenvolvida.

As línguas europeias ocidentais possuem uma categoria amplamente diferenciada de tempo nos verbos; a maioria das línguas eslavas apresenta, todavia, a categoria adicional dos aspectos. A sequência de ações que em um texto original da Europa ocidental pode ser especificada com 6 a 8 tempos verbais é apreendida na tradução eslava em geral com 3 tempos; os períodos que faltam são compensados através do uso de prefixos de aspecto ou de advérbios de tempo. Num propósito semelhante, também é preciso compensar recursos lexicais e estilísticos. O inglês e o russo têm a vantagem de serem compostos de duas camadas lexicais diferentes (respectivamente, a românica e a germânica, a eslávica eclesiástica e a russa), as línguas eslavas são, ademais, ricas em palavras com variadas nuances de sensibilidade, desde apelidos carinhosos no diminutivo até modificações ironizantes. Ao alemão, as palavras compostas e a troca dos prefixos oferecem possibilidades específicas. As palavras eslavas podem nuançar sutilmente os significados por meio de prefixos, sufixos e alterações da raiz da palavra. 
Weitaus trügerischer und heimtückischer ist die Kategorie C. Jeder durchschnittliche Übersetzer sucht unter dem Druck des Originals Wege, wie er die Aussagewerte des Originaltextes ersetzen könnte. Dabei wird er sich jedoch bei einer rein intuitiven Anschauung zweier miteinander zusammenhängender Realitäten nicht bewußt: 1. Würde er nicht diejenigen spezifischen Mittel seiner Sprache nutzen, für die es im Original keine Grundlage geben kann, so wäre die Ausdrucksskala der Übersetzung ärmer als die der Originalliteratur, die in der Sprache des Übersetzers abgefaßt ist (nur die Kategorie A, statt A + C); 2. in der Vorlage sind einige semantische und stilistische Werte latent, nämlich solche, die Bestandteil der Mitteilungsabsicht und der stilistischen Zielsetzung des Werkes sind, die der Autor aber aus sprachlichen Gründen nicht ausdrücken konnte. Manchmal kann der Übersetzer diese latenten Bedeutungen des Originals enthüllen und mit seinen reicheren Ausdrucksmitteln deutlich machen.

Auf diese Feststellung zielen sehr genau die Bemerkungen Fritz Güttingers:

Wie kann man eine Übersetzung beurteilen, ohne davon mehr als zwei oder drei Seiten zu lesen, und ohne diese mit dem Original vergleichen zu müssen? Es gibt da eine einfache Stichprobe. Man braucht sich nur zu fragen, welches die im Deutschen häufigsten Wörter sind, die es in der anderen Sprache nicht gibt, und man hat ein Mittel, um festzustellen, ob eine Übersetzung etwas taugt oder nicht. ${ }^{10}$

Im großen Ganzen kann man sagen, daß der Übersetzer sich gegenüber dem Originalautor in seiner Sprache in einem Raum verengter Auswahlmöglichkeiten befindet (Kategorie A) und umgekehrt wiederum bemüht ist, seine Möglichkeiten über das übliche Inventar hinaus auszuweiten, aus dem der Schriftstel-
Muito mais ilusória e traiçoeira é a categoria C. Qualquer tradutor mediano busca, sob a pressão do original, caminhos pelos quais possa restituir os valores informativos do texto original. Entretanto, com um ponto de vista meramente intuitivo de duas realidades interligadas, ele não se dá conta de que: $1^{\circ}$ ) se ele não utilizasse aqueles recursos específicos de sua língua para os quais não pode haver fundamento no original, então a escala de expressão da tradução seria mais pobre do que a da literatura original escrita na língua do tradutor (somente a categoria A, em vez de A $+\mathrm{C}) ; 2^{\circ}$ ) no modelo, alguns valores semânticos e estilísticos são latentes, aqueles que fazem parte da intenção informativa e da meta estabelecida para a obra em termos de estilo, que o autor, porém, por razões relacionadas ao idioma, não pode expressar. Muitas vezes o tradutor pode revelar estes sentidos latentes do original e tornar claros com seus recursos expressivos mais ricos.

As observações de Fritz Güttinger apontam exatamente para esta constatação:

Como se pode julgar uma tradução sem ler mais do que duas ou três linhas e sem compará-la com o original? Existe nesse caso uma prova simples, por amostragem aleatória. Basta se perguntar quais são as palavras mais frequentes no alemão que não existem nas outras línguas, e encontra-se um meio para determinar se uma tradução serve para algo ou não. ${ }^{10}$

No geral, pode-se dizer que o tradutor, comparado ao autor original em sua língua, encontra-se num espaço de limitadas opções de escolha (categoria A), mas tenta, por sua vez, ampliar suas opções para além do inventário usual do qual o escritor se nutre (isto é, de $\mathrm{A}+\mathrm{C}$ para $\mathrm{A}+\mathrm{B}+\mathrm{C}$ ). Esta é a expressão es-

\footnotetext{
${ }^{10}$ F. GÜTTINGER. op. cit. 143.
} 
ler schöpft (d. i. von A + C nach A $+B+C$ ). Das ist der schematische Ausdruck jener Erprobung sprachlicher Möglichkeiten über die in der heimischen Literatur bewährten Grenzen hinaus, zu welcher der Übersetzer sich gezwungen sieht.

b) Der Stil des Übersetzers trägt letztlich immer die Spuren des Sichentscheiden-Müssens unter dem Einfluß der Vorlage. Es gibt einen direkten und einen indirekten Einfluß des Sprachausdrucks des Originals auf die Übersetzung, was positive und negative Wirkungen hat. Und zwar äußert sich der direkte Einfluß durch das Vorhandensein unorganischer Konstruktionen, die nach dem Original geschaffen sind, und durch die Abwesenheit derjenigen deutschen Ausdrucksmittel, über die die Sprache der Vorlage nicht verfügt. Mit diesen sprachlichen Erscheinungen werden wir uns nicht ausführlich befassen, denn es gibt hierüber eine umfangreiche Literatur.

Umgekehrt zeigt sich der indirekte Einfluß des Originals in dem Bemühen des Übersetzers, sich von den Stileigenheiten des Originals zu lösen, die er für grammatikalisch und nicht kennzeichnend hält. Besonders die begabteren und theoretisch mit den Ausdrucksmöglichkeiten der Ausgangssprache vertrauten Übersetzer weichen vielfach solchen Mitteln ängstlich aus.

Erfahrene Übersetzer aus dem Russischen umgehen beispielsweise das typisch russische Adverbialpartizip in einem Maße, daß die Frequenz der Partizipien bei ihnen niedriger ist als in der originalen Prosa. Selbst wenn sie normalerweise vielleicht konjunktionslose Konstruktionen (Und sieh - vor ihm ein flammender Busch), negative Umschreibungen (in einem nicht groBen Häuschen), Asyndeta (Der Krieg geht zu Ende, der Mann kehrt zurück) verwenden würden, weichen sie manchmal diesen für das Russische als charakteristisch empfundenen sprachlichen quemática daquela experimentação de possibilidades linguísticas que vão além dos limites estabelecidos na literatura nacional, à qual o tradutor se vê forçado.

b) O estilo do tradutor sempre trará, em última análise, traços da necessária tomada de decisão sob a influência do modelo. Há uma influência direta e uma indireta da expressão linguística do original sobre a tradução, o que possui efeitos positivos e negativos. Precisamente, a influência direta se manifesta pela presença de construções inorgânicas que são criadas seguindo o original e pela ausência daqueles recursos expressivos em alemão de que a língua do modelo não dispõe. Não nos ocuparemos demasiadamente destes fenômenos linguísticos, visto haver uma extensa literatura sobre este assunto.

Em contrapartida, a influência indireta do original mostrase naquele esforço do tradutor de se desprender das peculiaridades de estilo do original, as quais este considera gramaticais e não distintivas. Principalmente os tradutores mais talentosos e teoricamente familiarizados com as possibilidades expressivas da língua de partida desviam-se frequentemente de tais recursos, temerosos.

Tradutores experientes do russo evitam, por exemplo, o particípio adverbial tipicamente russo de tal forma que a frequência dos particípios nestes casos é menor do que na prosa original. Mesmo nos casos em que normalmente utilizariam construções sem conjunção ("E veja - diante dele um arbusto em chamas"), paráfrases negativas ("em um banheiro não muito grande"), assíndetos ("a guerra acaba, o homem retorna"), evitam-nas por serem caracteristicamente entendidas como recursos linguísticos do russo, assim como tradutores do inglês evitam 
Mitteln aus, ähnlich wie Übersetzer aus dem Englischen manchmal das Understatement vermeiden.

c) Außer den Schwierigkeiten, die sich aus der Inkongruenz zweier Sprachen und aus der Einwirkung der sprachlichen Fassung der Vorlage auf die Übersetzung ergeben, erwachsen dem Übersetzer gewisse sprachliche Nachteile daraus, daß der Ausdruck der Übersetzung nicht genuin ist, daß der Gedanke ex post in ein Material umgeformt wurde, in dem und für das er ursprünglich nicht geschaffen worden war. Hieraus folgt, daß der sprachliche Ausdruck im übersetzten Werk nicht absolut ist, sondern eine von vielen Möglichkeiten darstellt.

In Paul Eluards Les sentiers et les routes de la poésie gibt es Teile, die offensichtlich gegen die Entfremdung der Sprache gerichtet sind, dagegen, daß der Mensch die Sprache nur als ein graues, abstraktes Zirkulationsmittel für den Austausch von Gedanken ansieht. Er macht auf den sachlichen Gehalt und die organische Struktur des sprachlichen Ausdrucks dadurch aufmerksam, daß er den automatisierten Redensarten ihre ursprüngliche Bedeutung wiederverleiht:

Le baron était fait au tour du monde de l'amiral Anson; il avait la tête verte, un front de bataillon, des yeux d'écrevisse, le nez partout, une bouche en coeur, une langue de feu, une gorge de montagne et un magnifique palais.

Die Übersetzer müßten hier, ebenso wie Eluard, der Sprache ihren $\mathrm{Be} \cdot$ deutungsreichtum zurückgeben, der sprachlichen Produktivität den Weg öffnen - und dies ist in einer Zeit der sprachlichen Klischees nicht ohne Bedeutung.

Während das Originalwerk der Nationalsprache entwächst und von ihr mitgeformt wird, sind in der Übersetzung durch die eventualmente a atenuação (understatement).

c) Além das dificuldades que decorrem da incongruência de duas línguas e da influência da versão linguística do modelo sobre a tradução, surgem certas desvantagens linguísticas para o tradutor, visto que a expressão da tradução não é genuína, que o pensamento ex post é transformado em um material no qual e para o qual ele originariamente não fora criado. Decorre daí que a expressão linguística na obra traduzida não é absoluta, mas sim representa uma de muitas possibilidades.

Em Les sentiers et les routes de la poésie, de Paul Eluard, há partes que estão abertamente dirigidas contra a alienação da língua, opondo-se a que as pessoas considerem a língua simplesmente como um meio de circulação indistinto, abstrato para a troca de ideias. Ele chama a atenção para o teor objetivo e para a estrutura orgânica da expressão linguística devolvendo aos fraseologismos automatizados seu significado original.

Le baron était fait au tour du monde de l'amiral Anson; il avait la tête verte, un front de bataillon, des yeux d'écrevisse, le nez partout, une bouche en coeur, une langue de feu, une gorge de montagne et un magnifique palais.

Os tradutores, assim como Eluard, teriam que nesse caso restituir à língua sua riqueza de significados, abrir caminho para a produtividade linguística - e isso, numa época de clichês linguísticos, não é algo sem importância.

Enquanto a obra original se desenvolve diferenciando-se em relação à língua nacional e é formada com a participação de- 
Sprache vermittelte künstlerische Bereicherungen seltene Ausnahmen, kein genereller Bestandteil des Schöpferprozesses, sondern nur das Ergebnis sprachlicher Zufälligkeiten.

So ergab sich aus dem Klangmaterial der französischen Sprache für alle Übersetzer des tschechischen romantischen Poems Mai von Karel Hynek Macha ins Französische (H. Jelínek J. Pasquier und J. Hořejší - A. Castagnou) ein Klangspiel, das mit dem euphonischen Aufbau des Gedichts übereinstimmt und hilft, die Klangfolgen, die sonst verloren gehen, zu kompensieren:

$$
\text { Je pozdní večer - druhý máj Le temps de Mai ... le temps d'aimer }
$$$$
\text { Večerní máj - je lásky čas C'est la fin d'un so ir ... le deux Mai, }
$$

\section{(Spätabend ist's - der zweite Mai,}

Ein Abendmai - er Liebe Zeit;)

(Eduard Neumann)

Die Notwendigkeit, die Gedanken des Originals in einer Sprache zu reproduzieren, die sich manchmal nur der Gewalt fügt, führt zu einer Reihe von handwerklichen Manipulationen, zu sprachlichen Kompromissen, die solche Konstruktionen lösen sollen, für die die Sprache des Übersetzers keine autochthonen Konstruktionen bietet. Zur Überbrückung der Kluft zwischen dem Ausdrucksvermögen zweier Sprachen schaffen sich die Übersetzer häufig ein für allemal stilistische Klischees, Konstruktionen, denen man Spuren der Gewaltanwendung anmerkt, die nötig war, um der Muttersprache fremde Gedankenformulierungen aufzuzwingen. Der übersetzte Text läßt sich dann gewöhnlich auf den ersten Blick an der Häufung gewisser Fügungen erkennen, die man zwar als grammatisch und stilistisch korrekt, aber doch als etwas gekünstelt empfindet. la, na tradução enriquecimentos artísticos transmitidos pela língua são raras exceções, não são componentes comuns do processo criativo, e sim apenas resultado de casualidades linguísticas.

Então, a partir do material sonoro da língua francesa, todos os tradutores do poema romântico tcheco "Mai", de Karel Hynek Macha, para o francês (H. Jelínek, J. Pasquier e J. Hořejší; A. Castagnou) chegaram a um jogo sonoro que coincide com a estrutura eufônica do poema e ajuda a compensar as sequências de sons que de outro modo se perderiam.

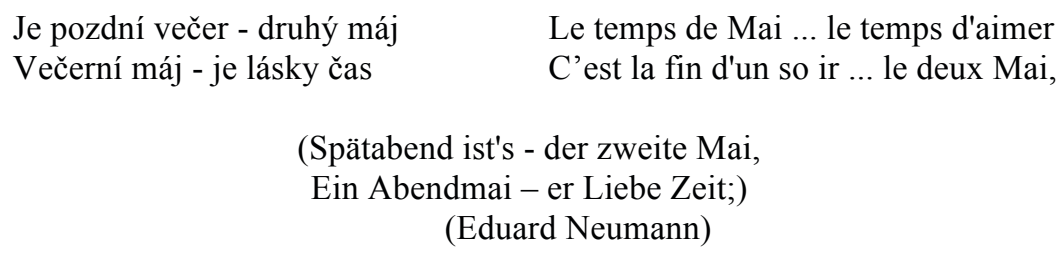

A necessidade de reproduzir as ideias do original em uma língua que às vezes só se submete à força, leva a uma sequência de manipulações de artífice, compromissos linguísticos que devem solucionar tais construções para as quais a língua do tradutor não oferece construções autóctones. Para ultrapassar o abismo entre as possibilidades expressivas das duas línguas, os tradutores criam para si, muitas vezes definitivamente, clichês estilísticos, construções que deixam transparecer os vestígios do uso da força que foi necessária para impor à língua materna formulações de ideias estrangeiras. O texto traduzido se deixa, então, em geral ser reconhecido à primeira vista pela frequência de certas construções que, apesar de estarem gramatical e estilisticamente corretas, dão a sensação de algo artificial. 
Stereotype Lösungen bestimmter Situationen sind die Folge einer mangelnden schöpferischen Begabung und erscheinen in analoger Form auch bei einer zweiten der reproduzierenden Künste - der Schauspielkunst.

Die Vertreter der darstellenden Kunst verhalten sich genau so wie ihr: sie bemühen sich, in sich selbst die typisch menschlichen Züge wachzurufen und einzufangen, die das innere Leben einer Rolle ausmachen. Nachdem er für jede von ihnen ein für allemal die beste Form geschaffen hat, lernt sie der Schauspieler in Wirklichkeit nur mechanisch, um sie im Augenblick seines öffentlichen Auftretens ohne Beteiligung der Sinne zu reproduzieren ... Es gibt eine eigene handwerkliche Manier der Rollendarstellung, eine Manier der Stimme, der Diktion und der Intonation ... Es gibt Ausdrucksmittel für die Gangart (in der Routine erstarrte Schauspieler gehen nicht, sondern sie schreiten über die Bretter der Bühne), für die Bewegungen und Handlungen, für die Plastik und das Spiel der Äußerlichkeiten (diese sind besonders bezeichnend für die handwerklichen Schauspieler; sie sind nicht auf Schönheit sondern, auf Gefälligkeit begründet). Es gibt Mittel, um alle möglichen menschlichen Gefühle und Leidenschaften auszudrücken (Zähnefletschen, Augenrollen bei Eifersucht, so wie es Nazvanov tat, Bedecken der Augen und des Gesichts mit den Händen anstelle des Weinens, das Raufen der Haare bei Verzweiflung). Es gibt Mittel der Darstellung ganzer Typen und Gestalten der verschiedenen Gesellschaftsschichten (Bauern spucken auf den Fußboden, wischen sich die Nase mit dem Rockärmel ab, Soldaten klirren mit den Sporen, Aristokraten spielen mit der Lorgnette); es gibt Mittel, Epochen darzustellen (Operngesten für das Mittelalter, der Tanzschritt für das 18. Jahrhundert); wir kennen Mittel zur Verkörperung von Stücken und Rollen (des Vorstehers in Gogols Revisor); die eigentümliche Wendung des Körpers zum Zuschauerraum und das Anlegen der Handfläche an den Mund beim Zurseitesprechen. All diese Ausdrucksmittel wurden mit der Zeit Tradition ... Durch alle diese äußeren Ausdruckselemente wollen die handwerklich veranlagten Schauspieler ursprüngliches Erleben und schöpferische Leistung ersetzen. $^{11}$
Soluções estereotípicas de determinadas situações são a consequência de uma falta de talento criativo e aparecem, de forma análoga, também em um outro caso de arte reprodutiva na atuação teatral.

Os representantes das artes cênicas comportam-se exatamente como vocês: esforçam-se em evocar e captar em si mesmos os traços tipicamente humanos, apagando a vida interior de um papel. Depois de ter criado para cada um deles, de uma vez por todas, a melhor forma, o ator na verdade a estuda apenas maquinalmente, para reproduzi-la diante de seu público sem interferência dos sentidos... Há um estilo artesanal próprio de representação do papel, um estilo de voz, de dicção, de entonação... Há recursos expressivos para caminhar (atores vencidos pela rotina não andam, e sim marcham sobre o tablado), para os movimentos e ações, para a plasticidade e para o jogo de enunciados (estes são principalmente característicos do ator com cuidados artesanais; eles não têm por base a beleza, mas sim o agrado). Há recursos para expressar todos os sentimentos e paixões humanas possíveis (mostrar os dentes, revirar os olhos em caso de ciúme, como fez Nazvanov, cobrir os olhos e o rosto com as mãos em vez de chorar, arrancar os cabelos em momento de desespero). Há recursos de representação de todos os tipos e personagens das diferentes classes sociais (camponeses cospem no chão, limpam o nariz na manga do casaco, soldados batem com as esporas, aristocratas brincam com o lornhão); há recursos para representar épocas (gestos de ópera para a Idade Média, passos de dança para o século 18); conhecemos recursos para incorporar peças e funções (como o inspetor em $O$ Inspetor Geral, de Gogol); a peculiar virada do corpo para o auditório e o movimento de posicionar a mão junto a um canto da boca ao se fazer um aparte. Todos estes recursos expressivos, com o tempo, se tornaram tradição... Por meio de todos estes elementos expressivos externos, os atores com inclinação para cuidados artesanais pretendem substituir a experiência original e o trabalho criativo. ${ }^{11}$

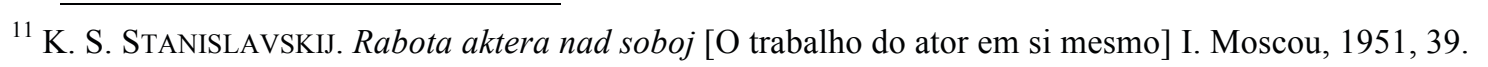


Auch der Übersetzer hat seine Schablonen, Chargen, von denen sich viele nicht einmal aus der objektiven Begrenztheit seines Könnens ergeben, sondern aus seiner Unbeweglichkeit. Weil er gewöhnlich eine geringere schöpferische Begabung hat als der Originalautor, übernimmt er in erhöhtem Maße die auch in der Originalliteratur gebräuchlichen Schablonen: zur Archaisierung der Sprache verwendet er eine begrenzte Zahl von Standardmitteln (z. B. im Englischen die Endungen -eth), für die sprachliche Karikatur in der Regel immer den gleichen Dialekt usw. Im Gegensatz zum Originalautor, der sich sprachlich immer weiterentwickelt und zu denen gehört, die an der Entwicklung der Nationalsprache arbeiten, steht der Übersetzer sehr häufig im Banne der Stilmittel, die in seiner Jugend gebräuchlich waren, und er arbeitet jahrzehntelang mit einer unveränderten Sprache. Deswegen veraltet auch die Übersetzung gewöhnlich schneller als das Original.

Noch offenkundiger ist das Fehlen eines ursprünglichen Schöpfertalents bei feineren und schwierigeren Stilmitteln. In übersetzten Versen finden wir nicht selten die Spuren überlebter Gedichtstile, die durch ihr $>$ poetisches Gehabe $<$ die Übersetzung entwerten. Besonders bei der alten und formal strengen Poesie verführt oft das unbedingte Streben nach einer dichterischen Diktion auch gute Übersetzer zu einem unangemessenen Poetisieren.

Hier belehren wiederum die in der Schauspielkunst parallel auftretenden Manierismen. G. Bojadžijev ${ }^{12}$ charakterisiert drei Typen einer schlechten schöpferischen Arbeit des Schauspielers:
Também o tradutor possui seus clichês, expedientes secundários dos quais muitos nem sequer resultam da limitação objetiva de suas habilidades, mas sim de sua imobilidade. Por habitualmente ter um talento criativo menor do que o autor original, ele adota, em grande medida, os clichês também usuais na literatura original: para dar uma feição arcaizante à língua, utiliza um número limitado de recursos padrão (por exemplo, a terminação eth em inglês), para a caricatura da língua, geralmente sempre o mesmo dialeto, etc. Ao contrário do autor original, que está sempre se aperfeiçoando linguisticamente e trabalha para o desenvolvimento da língua nacional, o tradutor muito frequentemente permanece sob o encanto dos recursos estilísticos que eram usuais em sua juventude e trabalha durante décadas com uma língua inalterada. É por isso também que a tradução habitualmente envelhece mais rápido que o original.

Ainda mais notória é a falta de um talento criativo original no caso de recursos estilísticos mais sutis e difíceis. Em versos traduzidos não é raro encontrarmos vestígios de estilos poéticos antiquados, que, por sua "afetação poética", diminuem o valor da tradução. Principalmente na poesia antiga e formalmente rígida, a busca incondicional por uma dicção poética muitas vezes desencaminha até mesmo bons tradutores para uma poetização inadequada.

Aqui novamente aprendemos com os inúmeros maneirismos que ocorrem paralelamente nas artes cênicas. G. Bojadžijev $^{12}$ caracteriza três tipos de um mau trabalho criativo do ator:

\footnotetext{
${ }^{12}$ G. BoJADŽIJEV. Poezija teatra [A poesia do teatro]. Moscou, 1960, 81.
} 
1. Der Manierismus: anstatt auf die schöpferische Phantasie verläßt sich der Schauspieler auf sein professionelles Gedächtnis und seine Angewohnheiten; er drückt keineswegs den wirklichen Charakter der Gestalten aus, sondern seine banalen Vorstellungen von den Menschen; und die hat er entweder bei anderen Theatervorstellungen abgeschaut, oder er wiederholt beharrlich eine Ausdrucksform, die er sich einmal geschaffen hat. Man vergleiche das banale $>$ Poetisieren $<$, die Sentimentalität und die Manierismen in der Übersetzung.

2. Die äußere Charakterisierung der Gestalten: aus Freude darüber, daß er irgendeinen Charakterzug der Gestalt erfaßt hat, ordnet der Schauspieler seine ganze Leistung diesem Charakterzug unter und schafft damit eine anekdotische Figur; er richtet sich somit keineswegs nach dem Charakter in seiner Gesamtheit, sondern nach seiner einseitigen theoretischen Vorstellung von diesem Charakter. - Man vergleiche das $>$ Nachzeichnen $<$ der sprachlichen Charakteristik der Personen, die Verstärkung intensiver Ausdrücke, die überflüssigen Diminutiva in den Übersetzungen von Kinderliteratur usw.

3. Das >natürliche Spiel<: in dem Streben nach Wahrhaftigkeit des Ausdrucks handelt der Schauspieler nach seiner eigenen Natur, er ist $>$ er selbst $<$ und erlebt subjektiv die dargestellten Gefühle; das Ergebnis ist eine Nivellierung der Gestalten. Ganz ähnlich verhält es sich bei der stilistischen Nivellierung der Vorlagen durch den eigenen Stil des Übersetzers.

Dort, wo dem Übersetzer mehrere stilistische Möglichkeiten zur Verfügung stehen, und wo er nach den Erfordernissen des
1. O maneirismo: em lugar da fantasia criativa, o ator confia em sua memória profissional e seus costumes; ele não expressa de maneira nenhuma o verdadeiro caráter das personagens, mas sim suas ideias banais acerca das pessoas; seja copiando de outras apresentações teatrais, seja repetindo persistentemente uma forma expressiva que ele certa vez tenha criado. Comparese a isso a "poetização" banal, o sentimentalismo e os maneirismos na tradução.

2. A caracterização externa das personagens: contente por ter apreendido algum traço de caráter da personagem, o ator submete todo o seu desempenho a este traço de caráter e cria, assim, uma figura anedótica; ele não se guia, deste modo, pelo caráter em sua totalidade, mas pela concepção teórica unilateral que tem desse caráter. Compare-se a isso a "imitação" dos aspectos característicos da linguagem das pessoas, a amplificação de expressões intensas, o excesso de diminutivos em traduções de literatura infantil, etc.

3. O "jogo natural": na busca pela veracidade da expressão, o ator age segundo sua própria natureza, ele é "ele mesmo" e experimenta subjetivamente as emoções representadas; o resultado é um nivelamento das personagens. Algo bem semelhante se dá no nivelamento estilístico do modelo pelo estilo próprio do tradutor.

É na circunstância em que o tradutor possui diversas possibilidades estilísticas à disposição e precisa decidir entre elas se- 
Kontextes zwischen ihnen entscheiden muß, beginnt das Auffinden und Auswählen. An dieser Stelle endet das Handwerk und beginnt die Kunst. Hier läßt sich der Charakter der schöpferischen Arbeit des Übersetzers genauer bestimmen. Bei ihm geht es um ein Schöpfertum, in dem das Auffinden dem Auswählen untergeordnet ist, die inventive der selektiven Fähigkeit. Der Übersetzer braucht eine lebhafte sprachliche Phantasie und Erfindungsgabe, um sich mit ihrer Hilfe eine große Zahl von Ausdrucksmitteln zu schaffen und die Möglichkeit zu erhalten, aus ihnen das treffendste auszuwählen. Gleichzeitig aber muß er Geschmack und Disziplin besitzen, um sich nicht durch einen verlockenden Ausdruck von der Aufgabe des Reproduzierens abbringen zu lassen oder in stilistische Unebenheiten zu verfallen. Sehr oft stehen beide Fähigkeiten in einem unausgewogenen Verhältnis. Phantasielosigkeit, das Charakteristikum der unbegabten Übersetzer, ist der häufigere Fall. Umgekehrt sind schöpferische und sprachlich kühne Übersetzer manchmal nicht in der Lage, die Tragfähigkeit der originellen Sprachmittel, die sie verwenden, genügend verläßlich abzuschätzen und sich den stilistischen Intentionen des Autors unterzuordnen.

Eine uneingeschränkte Auswahlmöglichkeit zwischen den Stilmitteln hat der Übersetzer nur dort, wo es um die Entscheidung zwischen echten Bedeutungs- und stilistischen Synonymen geht. Da dies aber nur ein Ausnahmefall ist, kann in Wirklichkeit meist deshalb auf verschiedene Weise übersetzt werden, weil unsere Auffassung vom Werk nicht präzise und objektiv genug ist. Sonst würde der Kontext, die stilistische Absicht des Autors, kurz die Gesamtheit des Kunstwerks, die Auswahl der Wörter bzw. des komplizierteren Stilmittels eindeutig bestimmen. Je vollkommener der Übersetzer das Werk begreift, desto konsequenter kann er die Auswahl der übersetzerischen Mittel vorausbestimmen. Je größer sein künstlerisches und sprachliches Talent gundo as exigências do contexto que começa o processo de descobrir e selecionar. Nesse momento acaba o artesanato e começa a arte. É quando o caráter do trabalho artístico do tradutor se deixa definir mais precisamente. Trata-se de uma criatividade na qual o descobrir está subordinado ao selecionar, a capacidade inventiva à seletiva. $\mathrm{O}$ tradutor precisa de uma intensa imaginação e inventividade linguística para, com a ajuda destas, criar um grande número de recursos expressivos e obter a possibilidade de escolher entre estes o mais acertado. Mas, ao mesmo tempo, precisa ter gosto e disciplina para não se deixar afastar da tarefa de reproduzir por uma expressão sedutora ou incorrer em disparidades estilísticas. Muito freqüentemente, as duas capacidades estão em uma relação assimétrica. Falta de imaginação, o traço característico de tradutores sem talento, é o caso mais frequente. Por outro lado, tradutores criativos e linguisticamente ousados muitas vezes não estão em condições de avaliar de modo suficientemente confiável a suportabilidade dos recursos linguísticos originais que utilizam e se subordinar às intenções estilísticas do autor.

Somente nos casos em que se trata de se decidir entre sinônimos perfeitos quanto ao sentido e sinônimos perfeitos quanto ao estilo é que o tradutor possui uma ilimitada possibilidade de escolha entre os recursos estilísticos. Visto que este é apenas um caso excepcional, na verdade em geral é por não ser precisa e suficientemente objetiva a nossa compreensão da obra que se pode traduzir de maneiras diversas. Caso contrário, seriam o contexto, a intenção estilística do autor, em resumo, o conjunto da obra de arte, que definiriam de maneira unívoca a escolha de palavras ou eventualmente o recurso estilístico mais complicado. Quanto mais perfeitamente o tradutor compreende a obra, mais consistentemente ele consegue predefinir a escolha dos recursos tradu- 
ist, desto vollkommenere Mittel stehen ihm zur Erfassung dieser richtigen Interpretation zur Verfügung.

Die Forderungen, die an den Übersetzer herantreten, bestimmen auch näher, welche Art von Talent die Kunst des Übersetzens benötigt: vor allem sind dies die Vorstellungsgabe, die Fähigkeit zu objektivieren und die stilistische Begabung. tórios. Quanto maior for seu talento artístico e linguístico, mais perfeitos recursos estarão à sua disposição para a apreensão dessa correta interpretação.

Os requisitos que se colocam para o tradutor também determinam mais detalhadamente que tipo de talento a arte de traduzir demanda: acima de tudo, trata-se da imaginação, da capacidade de objetivar e do talento estilístico.

Jiř́i Levý (1926-1967)

Prof. doutor, Palacký University of Olomouc (1950-1963); Masaryk's University in Brno (1964-1967)

Fonte: Die literarische Übersetzung - Theorie einer Kunstgattung. Traduzido ao alemão por Walter Schamschula \& Jiři Levý. Frankfurt am Main: Athenäum Verlag, 1969, 42-64.

Tradução de:

Filipe Neckel

filipe_neckel@hotmail.com

Mestre egresso, Universidade Federal de Santa Catarina

Marcelo Rondinelli

rondinellimarcelo@yahoo.com

Doutorando, Universidade Federal de Santa Catarina 